\title{
Diagnosis and Treatment of Adults with Community-acquired Pneumonia
}

\section{An Official Clinical Practice Guideline of the American Thoracic Society and Infectious Diseases Society of America}

2 Joshua P. Metlay*, Grant W. Waterer*, Ann C. Long, Antonio Anzueto, Jan Brozek, Kristina Crothers, Laura A. Cooley, Nathan C. Dean, Michael J. Fine, Scott A. Flanders, Marie R. Griffin, Mark L. Metersky, Daniel M. Musher, Marcos I. Restrepo, and Cynthia G. Whitney; on behalf of the American Thoracic Society and Infectious Diseases Society of America

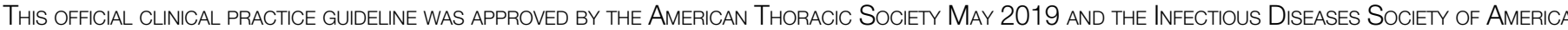
August 2019

Background: This document provides evidence-based clinical practice guidelines on the management of adult patients with community-acquired pneumonia.

Methods: A multidisciplinary panel conducted pragmatic systematic reviews of the relevant research and applied Grading of Recommendations, Assessment, Development, and Evaluation methodology for clinical recommendations.

Results: The panel addressed 16 specific areas for recommendations spanning questions of diagnostic testing, determination of site of care, selection of initial empiric antibiotic therapy, and subsequent management decisions. Although some recommendations remain unchanged from the 2007 guideline, the availability of results from new therapeutic trials and epidemiological investigations led to revised recommendations for empiric treatment strategies and additional management decisions.

Conclusions: The panel formulated and provided the rationale for recommendations on selected diagnostic and treatment strategies for adult patients with community-acquired pneumonia.

Keywords: community-acquired pneumonia; pneumonia; patient management

$\begin{array}{ll}\text { Contents } & \text { Question 1: In Adults with CAP, } \\ \text { Overview } & \text { Should Gram Stain and Culture } \\ \text { Introduction } & \text { of Lower Respiratory Secretions } \\ \text { Methods } & \text { Be Obtained at the Time of } \\ \text { Recommendations } & \text { Diagnosis? }\end{array}$

Question 2: In Adults with CAP,
Should Blood Cultures Be
Obtained at the Time of Diagnosis?
Question 3: In Adults with CAP,
Should Legionella and

\footnotetext{
${ }^{*}$ Co-first authors.
}

Endorsed by the Society of Infectious Disease Pharmacists July 2019.

ORCID IDs: 0000-0003-2259-6282 (J.P.M.); 0000-0002-7222-8018 (G.W.W.); 0000-0002-7007-588X (A.A.); 0000-0002-3122-0773 (J.B.);

0000-0001-9702-0371 (K.C.); 0000-0002-5127-3442 (L.A.C.); 0000-0002-1996-0533 (N.C.D.); 0000-0003-3470-9846 (M.J.F.);

0000-0002-8634-4909 (S.A.F.); 0000-0001-7114-7614 (M.R.G.); 0000-0003-1968-1400 (M.L.M.); 0000-0002-7571-066X (D.M.M.);

0000-0001-9107-3405 (M.I.R.); 0000-0002-1056-3216 (C.G.W.).

Supported by the American Thoracic Society and Infectious Diseases Society of America.

The findings and conclusions in this report are those of the authors and do not necessarily represent the official position of the U.S. CDC.

An Executive Summary of this document is available at http://www.atsjournals.org/doi/suppl/10.1164/rccm.201908-1581ST.

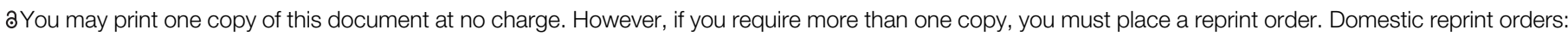
amy.schriver@sheridan.com; international reprint orders: louisa.mott@springer.com.

This article has an online supplement, which is accessible from this issue's table of contents at www.atsjournals.org. 
Pneumococcal Urinary Antigen

Testing Be Performed at the

Time of Diagnosis?

Question 4: In Adults with CAP, Should a Respiratory Sample Be Tested for Influenza Virus at the Time of Diagnosis?

Question 5: In Adults with CAP, Should Serum Procalcitonin plus

Clinical Judgment versus

Clinical Judgment Alone Be

Used to Withhold Initiation of

Antibiotic Treatment?

Question 6: Should a Clinical

Prediction Rule for Prognosis

plus Clinical Judgment versus

Clinical Judgment Alone Be

Used to Determine Inpatient

versus Outpatient Treatment

Location for Adults with CAP?

Question 7: Should a Clinical

Prediction Rule for Prognosis

plus Clinical Judgment versus

Clinical Judgment Alone Be

Used to Determine Inpatient

General Medical versus Higher
Levels of Inpatient Treatment Intensity (ICU, Step-Down, or Telemetry Unit) for Adults with CAP?

Question 8: In the Outpatient Setting, Which Antibiotics Are Recommended for Empiric Treatment of CAP in Adults?

Question 9: In the Inpatient Setting, Which Antibiotic Regimens Are Recommended for Empiric Treatment of CAP in Adults without Risk Factors for MRSA and $P$. aeruginosa?

Question 10: In the Inpatient Setting, Should Patients with Suspected Aspiration Pneumonia Receive Additional Anaerobic Coverage beyond Standard Empiric Treatment for CAP?

Question 11: In the Inpatient Setting, Should Adults with CAP and Risk Factors for MRSA or $P$. aeruginosa $\mathrm{Be}$ Treated with
Extended-Spectrum Antibiotic Therapy Instead of Standard CAP Regimens?

Question 12: In the Inpatient Setting, Should Adults with CAP Be Treated with Corticosteroids?

Question 13: In Adults with CAP Who Test Positive for Influenza, Should the Treatment Regimen Include Antiviral Therapy?

Question 14: In Adults with

CAP Who Test Positive for Influenza, Should the Treatment

Regimen Include Antibacterial

Therapy?

Question 15: In Outpatient and Inpatient Adults with CAP Who

Are Improving, What Is the

Appropriate Duration of

Antibiotic Treatment?

Question 16: In Adults with CAP

Who Are Improving, Should

Follow-up Chest Imaging Be Obtained?

Conclusions

\section{Overview}

In the more than 10 years since the last American Thoracic Society(ATS)/Infectious Diseases Society of America (IDSA) community-acquired pneumonia (CAP) guideline (1), there have been changes in the process for guideline development, as well as generation of new clinical data. ATS and IDSA agreed on moving from the narrative style of previous documents to the Grading of Recommendations Assessment, Development, and Evaluation (GRADE) format. We thus developed this updated CAP guideline as a series of questions answered from available evidence in an "is option A better than option B” format using the Patient or Population, Intervention, Comparison, Outcome (PICO) framework (2).

Given the expansion in information related to the diagnostic, therapeutic, and management decisions for the care of patients with CAP, we have purposely narrowed the scope of this guideline to address decisions from the time of clinical diagnosis of pneumonia (i.e., signs and symptoms of pneumonia with radiographic confirmation) to completion of

antimicrobial therapy and follow-up chest imaging. The document does not address either the initial clinical diagnostic criteria or prevention of pneumonia.

CAP is an extraordinarily heterogeneous illness, both in the range of responsible pathogens and the host response. Thus, the PICO questions we identified for this guideline do not represent the full range of relevant questions about the management of CAP but encompass a set of core questions identified as high priority by the panel. In addition, although each question was addressed using systematic reviews of available high-quality studies, the evidence base was often insufficient, emphasizing the continued importance of clinical judgment and experience in treating patients with this illness and the need for continued research.

\section{Introduction}

This guideline addresses the clinical entity of pneumonia that is acquired outside of the hospital setting. Although we recognize that CAP is frequently diagnosed without the use of a chest radiograph, especially in the ambulatory setting, we have focused on studies that used radiographic criteria for defining CAP, given the known inaccuracy of clinical signs and symptoms alone for CAP diagnosis (3). This guideline focuses on patients in the United States who have not recently completed foreign travel, especially to regions with emerging respiratory pathogens. This guideline also focuses on adults who do not have an immunocompromising condition, such as inherited or acquired immune deficiency or drug-induced neutropenia, including patients actively receiving cancer chemotherapy, patients infected with HIV with suppressed CD4 counts, and solid organ or bone marrow transplant recipients.

Antibiotic recommendations for the empiric treatment of CAP are based on selecting agents effective against the major treatable bacterial causes of CAP.

Traditionally, these bacterial pathogens include Streptococcus pneumoniae, Haemophilus influenzae, Mycoplasma pneumoniae, Staphylococcus aureus, Legionella species, Chlamydia pneumoniae, and Moraxella catarrhalis. The microbial etiology of CAP is changing, particularly with the widespread introduction of the pneumococcal conjugate vaccine, and there is increased recognition of the role of viral 
pathogens. The online supplement contains a more detailed discussion of CAP microbiology. As bacterial pathogens often coexist with viruses and there is no current diagnostic test accurate enough or fast enough to determine that CAP is due solely to a virus at the time of presentation (see below), our recommendations are to initially treat empirically for possible bacterial infection or coinfection. In addition, the emergence of multidrugresistant pathogens, including methicillinresistant $S$. aureus (MRSA) and Pseudomonas aeruginosa, requires separate recommendations when the risk of each of these pathogens is elevated. We acknowledge that other multidrug-resistant Enterobacteriaceae can cause CAP, including organisms producing extendedspectrum $\beta$-lactamase, but we do not discuss them separately because they are much less common and are effectively covered by the strategies presented for $P$. aeruginosa. Therefore, throughout this document when discussing $P$. aeruginosa we are also referring to other similar multiresistant gram-negative bacteria.

We have maintained the convention of separate recommendations on the basis of the severity of illness. Although historically site of care (outpatient, inpatient general ward, or ICU) has served as a severity surrogate, decisions about site of care may be based on considerations other than severity and can vary widely between hospitals and practice sites. We have therefore chosen to use the IDSA/ATS CAP severity criteria that have been validated and define severe CAP as present in patients with either one major criterion or three or more minor criteria. (Table 1)

This guideline reaffirms many recommendations from the 2007 statement. However, new evidence and a new process have led to significant changes, which are summarized in Table 2.

\section{Methods}

The guideline development methodology and how conflict of interest was managed are presented in the online supplement. In brief, the list of PICO questions was finalized based on a prioritization of the most important management decisions balanced against the decision to reduce the overall length of the document and total number of recommendations to maximize readability and usability. We followed the GRADE standards for evaluating the evidence for each PICO and assigned a quality of evidence rating of high, moderate, low, or very low. On the basis of the quality of evidence, recommendations were assigned as strong or conditional. In some cases, strong recommendations were made in the setting of low or very low quality of evidence in accordance with the GRADE rules for when such recommendations are allowable (e.g., when the consequences of the recommendation were high, such as preventing harm or saving life). In all other cases, recommendations that were based on low or very low quality of evidence and not believed to represent standards of care were labeled as conditional recommendations. Statements in favor of strong recommendations begin with the words "We recommend ..."; statements in favor of conditional recommendations begin with the words "We suggest ...." Although we specified pairwise PICO questions for all antibiotic options in the outpatient and inpatient settings, we summarized the recommendations using lists of treatment options, in no preferred order, rather than retain the PICO format for this section.

\section{Recommendations}

\section{Question 1: In Adults with CAP, Should Gram Stain and Culture of Lower Respiratory Secretions Be Obtained at the Time of Diagnosis?}

Recommendation. We recommend not obtaining sputum Gram stain and culture routinely in adults with CAP managed in the outpatient setting (strong recommendation, very low quality of evidence).

We recommend obtaining pretreatment Gram stain and culture of respiratory secretions in adults with CAP managed in the hospital setting who:

1. are classified as severe CAP (see Table 1), especially if they are intubated (strong recommendation, very low quality of evidence); or

2.

a. are being empirically treated for MRSA or $P$. aeruginosa (strong recommendation, very low quality of evidence); or b. were previously infected with MRSA or $P$. aeruginosa, especially those with prior respiratory tract infection (conditional recommendation, very low quality of evidence); or

c. were hospitalized and received parenteral antibiotics, whether during the hospitalization event or not, in the last 90 days (conditional recommendation, very low quality of evidence).

Summary of the evidence. Arguments for trying to determine the etiology of CAP are that 1) a resistant pathogen may be identified; 2) therapy may be narrowed; 3) some pathogens, such as Legionella, have public health implications; 4) therapy may be adjusted when patients fail initial therapy; and 5) the constantly changing epidemiology of CAP requires ongoing evaluation.

These arguments stand in contrast to the lack of high-quality evidence demonstrating that routine diagnostic testing improves individual patient outcomes. Studies that specifically evaluated the use of sputum Gram stain and culture alone (4-7), or in combination with other microbiological testing (8-11), also did not demonstrate better patient outcomes.

The overall poor yield of sputum evaluation for detecting organisms causing CAP limits its impact on management and patient outcomes. Obtaining a valid sputum specimen can be challenging because of patient-related characteristics (12-17). Performance characteristics of testing also vary by organism, receipt of prior antibiotics, and setting. For example, in patients with bacteremic pneumococcal pneumonia who have not received antibiotics, microscopic examination and culture of a good-quality sputum sample detects pneumococci in $86 \%$ of cases (18).

Rationale for the recommendation. In balancing the lack of evidence supporting routine sputum culture with the desire for improved antimicrobial stewardship, the committee voted to continue the stance of previous guidelines in recommending neither for nor against routinely obtaining sputum Gram stain and culture in all adults with CAP managed in the hospital setting. Whether to culture patients or not should be determined by individual clinicians on the basis of clinical presentation, local etiological considerations, and local antimicrobial stewardship processes.

The committee identified two situations in which we recommend sputum 
Table 1. 2007 Infectious Diseases Society of America/American Thoracic Society Criteria for Defining Severe Community-acquired Pneumonia

\section{Validated definition includes either one major criterion or three or more minor criteria}

Minor criteria
Respiratory rate $\geqslant 30$ breaths/min
$\mathrm{Pa}_{\mathrm{O} 2} / \mathrm{Fl}_{\mathrm{O} 2}$ ratio $\leqslant 250$
Multilobar infiltrates
Confusion/disorientation
Uremia (blood urea nitrogen
level $\geqslant 20 \mathrm{mg} / \mathrm{dl})$
Leukopenia* $($ white blood cell
count $<4,000 \mathrm{cells} / \mu \mathrm{l})$
Thrombocytopenia (platelet
count $<100,000 / \mu \mathrm{l})$
Hypothermia (core temperature $\left.<36^{\circ} \mathrm{C}\right)$
Hypotension requiring aggressive fluid
resuscitation
Major criteria
Septic shock with need for
vasopressors
Respiratory failure requiring mechanical
ventilation

*Due to infection alone (i.e., not chemotherapy induced).

Gram stain and culture: in hospitalized patients with severe CAP, and when strong risk factors for MRSA and $P$. aeruginosa are identified, unless local etiological data have already shown these pathogens are very infrequently identified in patients with CAP. Patients who have severe CAP requiring intubation should have lower respiratory tract samples, such as endotracheal aspirates, sent for Gram stain and culture promptly after intubation, particularly as these patients may be more likely to have pneumonia due to MRSA or $P$. aeruginosa, and endotracheal aspirates have a better yield of microbiological organisms than sputum culture (19).

We recommend obtaining sputum for Gram stain and culture in situations when risk factors for MRSA or $P$. aeruginosa are present, both when initial empiric therapy is expanded to cover these pathogens and when it is not expanded. In the former case, negative microbiological test results may be used to deescalate therapy, and in the latter case, positive microbiological test results may be used to adjust therapy. As discussed later, although there are numerous studies identifying individual risk factors for MRSA and $P$. aeruginosa, many of these associations are weak and vary across sites.
The most consistently strong risk factor to consider is prior infection with either MRSA or P. aeruginosa. In addition, hospitalization and treatment with parenteral antibiotics in the last 90 days is associated with an increased risk of these pathogens, and so we recommend sputum culture in this situation. These recommendations are not based on highgrade evidence but reflect the committee's desire to improve antibiotic use as well as improve clinicians' understanding of their local pathogen prevalences and resistance patterns, which we believe are key to selecting appropriate empiric antibiotic therapy.

Research needed in this area. Rapid, cost-effective, sensitive, and specific diagnostic tests to identify organisms causing CAP have potential to improve routine care by supporting the use of targeted therapy, especially when there are risk factors for antibiotic-resistant pathogens. All new diagnostic tests should be assessed in high-quality research studies that address the impact of testing strategies on treatment decisions and patient outcomes.

\section{Question 2: In Adults with CAP, Should Blood Cultures Be Obtained at the Time of Diagnosis?}

Recommendation. We recommend not obtaining blood cultures in adults with CAP managed in the outpatient setting (strong recommendation, very low quality of evidence).

We suggest not routinely obtaining blood cultures in adults with CAP managed in the hospital setting (conditional recommendation, very low quality of evidence).

We recommend obtaining pretreatment blood cultures in adults with CAP managed in the hospital setting who:

1. are classified as severe CAP (see Table 1) (strong recommendation, very low quality of evidence); or

2.

a. are being empirically treated for MRSA or P. aeruginosa (strong recommendation, very low quality of evidence); or

b. were previously infected with MRSA or $P$. aeruginosa, especially those with prior respiratory tract infection (conditional recommendation, very low quality of evidence); or c. were hospitalized and received parenteral antibiotics, whether during the hospitalization event or not, in the last 90 days (conditional recommendation, very low quality of evidence).

Summary of the evidence. There are no high-quality studies that specifically compared patient outcomes with and without blood culture testing. One large observational study found lower mortality for hospitalized patients associated with obtaining blood cultures at the time of admission (20). Three subsequent (smaller) observational studies found similar associations between in-hospital mortality and having blood cultures within 24 hours of admission, but the results were not statistically significant $(8,21,22)$.

The yield of blood cultures in most series of adults with nonsevere CAP is low, ranging from $2 \%$ (outpatients) to $9 \%$ (inpatients) $(14,21,23,24)$; furthermore, blood cultures rarely result in an appropriate change in empiric therapy (25), and blood specimens that include skin contaminants can generate false-positive test results. Growth of organisms such as coagulase-negative staphylococci, which are not recognized as CAP pathogens (26), may lead to inappropriate antimicrobial use that increases the risk for adverse drug effects. A study of adults hospitalized with CAP found blood cultures were associated with a significant increase in length of stay and duration of antibiotic therapy (27). Given the observational nature of these studies, it is unknown whether the associations found with blood cultures and patient outcomes were causal or due to unmeasured confounding factors, including severity of illness.

\section{Rationale for the recommendation.} Although additional diagnostic information could improve the quality of treatment decisions, support for routine collection of blood cultures is reduced by the low quality of studies demonstrating clinical benefit. Routinely obtaining blood cultures may generate falsepositive results that lead to unnecessary antibiotic use and increased length of stay.

In severe CAP, delay in covering lesscommon pathogens can have serious consequences. Therefore, the potential benefit of blood cultures is much larger when results can be returned within 24 to 48 hours.

The rationale for the recommendation for blood cultures in the setting of risk factors for MRSA and P. aeruginosa is the same as for sputum culture. 
Table 2. Differences between the 2019 and 2007 American Thoracic Society/Infectious Diseases Society of America Community-acquired Pneumonia Guidelines

\section{Recommendation \\ Sputum culture \\ 2007 ATS/IDSA Guideline \\ Primarily recommended in patients with severe disease}

Blood culture

Macrolide monotherapy

Use of procalcitonin

Use of corticosteroids

Use of healthcare-associated pneumonia category

Standard empiric therapy for severe CAP

Routine use of follow-up chest imaging
Primarily recommended in patients with severe disease

Strong recommendation for outpatients

Not covered

Not covered

Accepted as introduced in the 2005 ATS/IDSA hospital-acquired and ventilator-associated pneumonia guidelines

$\beta$-Lactam $/$ macrolide and $\beta$-lactam/fluoroquinolone combinations given equal weighting

Not addressed

2019 ATS/IDSA Guideline

Now recommended in patients with severe disease as well as in all inpatients empirically treated for MRSA or Pseudomonas aeruginosa

Now recommended in patients with severe disease as well as in all inpatients empirically treated for MRSA or $P$. aeruginosa

Conditional recommendation for outpatients based on resistance levels

Not recommended to determine need for initial antibacterial therapy

Recommended not to use. May be considered in patients with refractory septic shock

Recommend abandoning this categorization. Emphasis on local epidemiology and validated risk factors to determine need for MRSA or $P$. aeruginosa coverage. Increased emphasis on deescalation of treatment if cultures are negative

Both accepted but stronger evidence in favor of $\beta$-lactam/macrolide combination

Recommended not to obtain. Patients may be eligible for lung cancer screening, which should be performed as clinically indicated

Definition of abbreviations: ATS = American Thoracic Society; CAP = community-acquired pneumonia; IDSA=Infectious Diseases Society of America; MRSA = methicillin-resistant Staphylococcus aureus .

\section{Question 3: In Adults with CAP, Should Legionella and Pneumococcal Urinary Antigen Testing Be Performed at the Time of Diagnosis?}

Recommendation. We suggest not routinely testing urine for pneumococcal antigen in adults with CAP (conditional recommendation, low quality of evidence), except in adults with severe CAP (conditional recommendation, low quality of evidence).

We suggest not routinely testing urine for Legionella antigen in adults with CAP (conditional recommendation, low quality of evidence), except

1. in cases where indicated by epidemiological factors, such as association with a Legionella outbreak or recent travel (conditional recommendation, low quality of evidence); or
2. in adults with severe CAP (see Table 1) (conditional recommendation, low quality of evidence).

We suggest testing for Legionella urinary antigen and collecting lower respiratory tract secretions for Legionella culture on selective media or Legionella nucleic acid amplification testing in adults with severe CAP (conditional recommendation, low quality of evidence).

Summary of the evidence. Falguera and colleagues (28) randomized 177 patients to pathogen-directed treatment (targeted treatment) on the basis of results of urinary antigen testing for S. pneumoniae and Legionella versus empirical guidelinedirected treatment. Of the 88 patients in the targeted treatment arm, $25 \%$ had a positive urinary antigen test and received pathogendirected therapy. There were no statistical differences in death, clinical relapse, ICU admission, length of hospitalization, or length of antibiotic treatment (28). A second trial of 262 patients included a broader range of microbiological testing (sputum and blood cultures) and only Legionella urinary antigen testing, but patients receiving pathogen-directed therapy had similar clinical outcomes to patients receiving empirical, guidelinedirected therapy, including mortality, rates of clinical failure, and length of hospitalization (10).

One observational study evaluated cost and antibiotic selection in patients during two time periods, with and without pneumococcal urinary antigen testing, but found no differences during the two time periods (29). In contrast, other observational studies that have evaluated the impact of prior CAP guideline concordance (including initial diagnostic testing with urinary antigen tests and blood cultures, along with site of care 
Table 3. Initial Treatment Strategies for Outpatients with Community-acquired Pneumonia

\title{
Standard Regimen
}

\begin{abstract}
No comorbidities or risk factors for MRSA or Pseudomonas aeruginosa*
\end{abstract}

With comorbidities ${ }^{\ddagger}$

\author{
Amoxicillin or \\ doxycycline or \\ macrolide (if local pneumococcal \\ resistance is $<25 \%)^{\dagger}$
}

Combination therapy with amoxicillin/clavulanate or cephalosporin AND

macrolide or doxycycline ${ }^{\S}$

OR

monotherapy with respiratory fluoroquinolone

Definition of abbreviations: $\mathrm{ER}=$ extended release; MRSA = methicillin-resistant Staphylococcus aureus.

${ }^{*}$ Risk factors include prior respiratory isolation of MRSA or $P$. aeruginosa or recent hospitalization AND receipt of parenteral antibiotics (in the last $90 \mathrm{~d}$ ).

${ }^{\dagger}$ Amoxicillin $1 \mathrm{~g}$ three times daily, doxycycline $100 \mathrm{mg}$ twice daily, azithromycin $500 \mathrm{mg}$ on first day then $250 \mathrm{mg}$ daily, clarithromycin $500 \mathrm{mg}$ twice daily, or clarithromycin ER 1,000 mg daily.

${ }^{\ddagger}$ Comorbidities include chronic heart, lung, liver, or renal disease; diabetes mellitus; alcoholism; malignancy; or asplenia.

${ }^{\S}$ Amoxicillin/clavulanate $500 \mathrm{mg} / 125 \mathrm{mg}$ three times daily, amoxicillin/clavulanate $875 \mathrm{mg} / 125 \mathrm{mg}$ twice daily, 2,000 mg/125 mg twice daily, cefpodoxime $200 \mathrm{mg}$ twice daily, or cefuroxime $500 \mathrm{mg}$ twice daily; AND azithromycin $500 \mathrm{mg}$ on first day then $250 \mathrm{mg}$ daily, clarithromycin $500 \mathrm{mg}$ twice daily, clarithromycin ER 1,000 mg daily, or doxycycline $100 \mathrm{mg}$ twice daily.

"Levofloxacin 750 mg daily, moxifloxacin 400 mg daily, or gemifloxacin 320 mg daily.

stratification and guideline-concordant therapy) have reported reduced mortality for patients receiving prior CAP guidelineconcordant care, including diagnostic testing. Costantini and colleagues reported a $57 \%$ statistically significant reduced odds of in-hospital mortality for patients receiving pneumococcal and Legionella urinary antigen testing compared with patients not tested, adjusting for baseline demographic and clinical differences (27). Uematsu and colleagues reported 25\% reduced odds of 30-day mortality in patients receiving urinary antigen tests but no impact on length of hospitalizations (7). However, neither study distinguished whether the mortality benefits attributed to testing were a direct consequence of the test results or a marker of other improved processes of care.

\section{Rationale for the recommendation.} Randomized trials have failed to identify a benefit for urinary antigen testing for $S$. pneumoniae and Legionella. Concern has also been raised that narrowing therapy in response to positive urinary antigen tests could lead to increased risk of clinical relapse (28). In large observational studies, these diagnostic tests have been associated with reduction in mortality; therefore, we recommend testing in patients with severe disease. An increase in Legionella infections in the United States in the past decade highlights the importance of this diagnosis especially among severely ill patients, particularly in the setting of potential outbreaks due to a common source, although most cases are not associated with a known outbreak and remain sporadic $(30,31)$.

Research needed in this area. Newer nucleic acid amplification systems for sputum, urine, and blood are being developed and require rigorous testing to assess the impact on treatment decisions and clinical outcomes for patients with CAP, as well as the public health benefit in terms of prevention of additional cases and informing primary prevention strategies. In particular, we acknowledge the emergence of rapid, lowcost genomic sequence detection assays that have the potential to greatly improve pathogen-directed therapy and thereby improve antimicrobial stewardship.

\section{Question 4: In Adults with CAP, Should a Respiratory Sample Be Tested for Influenza Virus at the Time of Diagnosis?}

Recommendation. When influenza viruses are circulating in the community, we recommend testing for influenza with a rapid influenza molecular assay (i.e., influenza nucleic acid amplification test), which is preferred over a rapid influenza diagnostic test (i.e., antigen test) (strong recommendation, moderate quality of evidence).

Summary of the evidence. Rapid influenza tests have become increasingly available, moving from earlier antigen-based detection tests to nucleic acid amplification tests. We were unable to identify any studies that evaluated the impact of influenza testing on outcomes in adults with CAP. In contrast, a substantial literature has evaluated the importance of influenza testing in the general population, specifically among patients with influenza-like illness (32). Our recommendations for influenza testing in adults with CAP are consistent with testing recommendations for the broader population of adults with suspected influenza, as summarized in the recent IDSA Influenza Clinical Practice Guideline (33).

Rationale for the recommendation. The benefits of antiviral therapy support testing of patients during periods of high influenza activity. During periods of low influenza activity, testing can be considered but may not be routinely performed. Of note, this testing recommendation has both therapeutic and infection-control implications in the hospital setting. Updated influenza testing recommendations are also available on the CDC website (https://www.cdc.gov/flu/professionals/ diagnosis/index.htm).

\section{Question 5: In Adults with CAP, Should Serum Procalcitonin plus Clinical Judgment versus Clinical Judgment Alone Be Used to Withhold Initiation of Antibiotic Treatment?}

Recommendation. We recommend that empiric antibiotic therapy should be initiated in adults with clinically suspected and radiographically confirmed CAP regardless of initial serum procalcitonin level (strong recommendation, moderate quality of evidence).

Summary of the evidence. Several studies have assessed the ability of procalcitonin to distinguish acute respiratory infections due to pneumonia (which are of viral or bacterial etiology) from acute bronchitis or upper respiratory tract infections (which are almost 


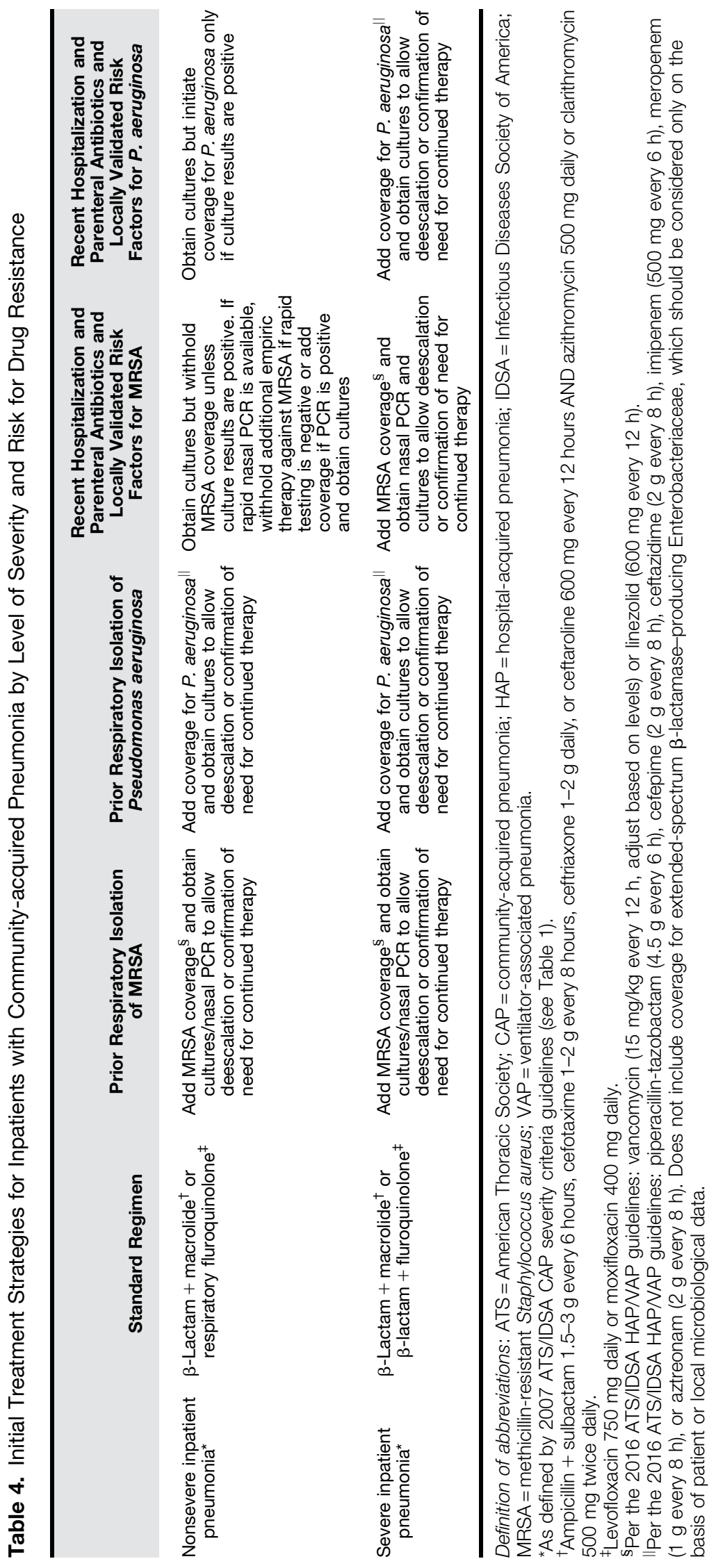


exclusively viral in etiology). However, for the purposes of this guideline, the question is whether, among patients with clinically confirmed CAP, measurement of procalcitonin can distinguish patients with viral versus bacterial etiologies and guide the need for initial antibiotic therapy. Some investigators have suggested that procalcitonin levels of $\leqslant 0.1 \mu \mathrm{g} / \mathrm{L}$ indicate a high likelihood of viral infection, whereas levels $\geqslant 0.25 \mu \mathrm{g} / \mathrm{L}$ indicate a high likelihood of bacterial pneumonia (34-36). However, a recent study in hospitalized patients with CAP failed to identify a procalcitonin threshold that discriminated between viral and bacterial pathogens, although higher procalcitonin strongly correlated with increased probability of a bacterial infection (37). The reported sensitivity of procalcitonin to detect bacterial infection ranges from $38 \%$ to $91 \%$, underscoring that this test alone cannot be used to justify withholding antibiotics from patients with CAP (38).

Rationale for the recommendation. Procalcitonin has been used to guide initiation of antibiotics in patients with lower respiratory infections, but many of these studies are not restricted to patients with radiographically confirmed pneumonia. Some patients with low procalcitonin levels have CAP and have been safely treated without antibiotics (35), but these represent small subgroups, raising concerns about the safety of widely using such a strategy.

Research needed in this area. Given the epidemiological evidence that viruses are an important cause of CAP, there is a critical need to validate the use of current rapid laboratory tests, including point-of-care tests, to accurately identify situations in which antibacterial therapy can be safely withheld among adults with CAP.

\section{Question 6: Should a Clinical Prediction Rule for Prognosis plus Clinical Judgment versus Clinical Judgment Alone Be Used to Determine Inpatient versus Outpatient Treatment Location for Adults with CAP?}

Recommendation. In addition to clinical judgement, we recommend that clinicians use a validated clinical prediction rule for prognosis, preferentially the Pneumonia Severity Index (PSI) (strong recommendation, moderate quality of evidence) over the CURB-65 (tool based on confusion, urea level, respiratory rate, blood pressure, and age $\geqslant 65$ ) (conditional recommendation, low quality of evidence), to determine the need for hospitalization in adults diagnosed with CAP.

Summary of the evidence. Both the PSI and CURB-65 were developed as prognostic models in immunocompetent patients with pneumonia, using patient demographic and clinical variables from the time of diagnosis to predict 30 -day mortality $(39,40)$. When compared with CURB-65, PSI identifies larger proportions of patients as low risk and has a higher discriminative power in predicting mortality (41).

Two multicenter, cluster-randomized trials demonstrated that use of the PSI safely increases the proportion of patients who can be treated in the outpatient setting $(42,43)$. These trials and one additional randomized controlled trial (RCT) support the safety of using the PSI to guide the initial site of treatment of patients without worsening mortality or other clinically relevant outcomes (42-44). Consistent evidence from three pre-post intervention studies and one prospective controlled observational study support the effectiveness and safety of using the PSI to guide the initial site of treatment (45-48).

Clinical severity is not the only consideration in determining the need for hospital admission $(49,50)$. Some patients have medical and/or psychosocial contraindications to outpatient therapy, such as inability to maintain oral intake, history of substance abuse, cognitive impairment, severe comorbid illnesses, and impaired functional status.

The PSI may underestimate illness severity among younger patients and oversimplify how clinicians interpret continuous variables (e.g., all systolic blood pressures $<90 \mathrm{~mm} \mathrm{Hg}$ are considered abnormal, regardless of the patient's baseline and actual measurement). Therefore, when used as a decision aid, the PSI should be used in conjunction with clinical judgment.

In comparison to the PSI, there is less evidence that CURB-65 is effective as a decision aid in guiding the initial site of treatment. One pre-post, controlled intervention study using an electronically calculated version of CURB-65, $\mathrm{Pa}_{\mathrm{O} 2} / \mathrm{FI}_{\mathrm{O} 2}<300$, absence of pleural effusion, and fewer than three minor ATS severity criteria observed no significant increase in the use of outpatient treatment for adults with CAP (51). A randomized trial compared the safety of inpatient versus outpatient treatment of 49 patients with CURB-65 scores of less than 2 (52) but had limited power to detect differences in patient outcomes; furthermore, outpatient treatment included daily nursing visits and parenteral antibiotic therapy that is typically restricted to inpatient care.

Rationale for the recommendation. Our recommendation to use the PSI as an adjunct to clinical judgment to guide the initial site of treatment is based on consistent evidence of the effectiveness and safety of this approach. Using a safe and effective decision aid to increase outpatient treatment of patients with CAP has potential to decrease unnecessary variability in admission rates, the high cost of inpatient pneumonia treatment $(53,54)$, and the risk of hospital-acquired complications. Providing a conditional recommendation to use CURB-65 considers its greater simplicity of use relative to the PSI despite the paucity of evidence regarding its effectiveness or safety.

Research needed in this area. It is important to study the effectiveness and safety of using CURB scores or new prediction rules for prognosis as decision aids to guide the initial site of treatment for patients with CAP compared with the PSI. Future studies of prediction rules should also test electronic versions generated in real time from data routinely recorded in the electronic medical record and assess their performance in patient populations excluded from the development of existing prediction rules $(55,56)$.

\section{Question 7: Should a Clinical Prediction Rule for Prognosis plus Clinical Judgment versus Clinical Judgment Alone Be Used to Determine Inpatient General Medical versus Higher Levels of Inpatient Treatment Intensity (ICU, Step- Down, or Telemetry Unit) for Adults with CAP?}

Recommendation. We recommend direct admission to an ICU for patients with hypotension requiring vasopressors or respiratory failure requiring mechanical ventilation (strong recommendation, low quality of evidence).

For patients not requiring vasopressors or mechanical ventilator support, we suggest 
using the IDSA/ATS 2007 minor severity criteria (Table 1) together with clinical judgment to guide the need for higher levels of treatment intensity (conditional recommendation, low quality of evidence).

Summary of the evidence. The PSI and CURB-65 were not designed to help select the level of care needed by a patient who is hospitalized for CAP. Several prognostic models have been designed to predict the need for higher levels of inpatient treatment intensity using severity-of-illness

parameters based on patient outcomes (ATS 2001, IDSA/ATS 2007, SMART-COP, and SCAP score). Studies of prognostic models have used different end points, including inpatient mortality $(57,58)$, ICU admission (57-59), receipt of intensive respiratory or vasopressor support $(59,60)$, or ICU admission plus receipt of a critical therapy (61). In comparative studies, these prognostic models yield higher overall accuracy than the PSI or CURB-65 when using illness outcomes other than mortality $(58,59,61)$.

The 2007 IDSA/ATS CAP guidelines recommended a set of two major and nine minor criteria to define severe pneumonia requiring ICU admission (Table 1). These criteria were based on empirical evidence from published studies and expert consensus. All elements are routinely available in emergency department settings and are electronically calculable $(51,61)$.

Several groups have validated these criteria in pneumonia cohorts from different countries $(57-59,61)$, with a meta-analysis reporting one major or three minor criteria had a pooled sensitivity of $84 \%$ and a specificity of $78 \%$ for predicting ICU admission (62). Without the major criteria, a threshold of three or more minor criteria (recommended in the 2007 IDSA/ATS guideline) had a pooled sensitivity of $56 \%$ and specificity of $91 \%$ for predicting ICU admission (63).

SMART-COP is an alternative, validated prediction rule for identifying patients with pneumonia who need vasopressor support and/or mechanical ventilation. The eight SMART-COP criteria and the nine 2007 IDSA/ATS minor criteria have five overlapping elements: hypoxia, confusion, respiratory rate, multilobar radiographic opacities, and low systolic blood pressure. SMART-COP had a pooled sensitivity of $79 \%$ and specificity of $64 \%$ in predicting ICU admission using a threshold of three or more criteria but uses albumin,
$\mathrm{Pa}_{\mathrm{O} 2}$, and $\mathrm{pH}$, which are not universally available for real-time clinical decisionmaking (60). For predicting ICU admission, one comparison reported equivalence of the IDSA/ATS minor criteria and SMART-

COP (63) and another reported a significantly greater performance of the IDSA/ATS minor criteria (61). No randomized studies have evaluated the effectiveness or safety of an illness severity tool as a decision aid to guide the intensity of inpatient treatment for patients hospitalized with CAP.

\section{Rationale for the recommendation.}

Patients transferred to an ICU after admission to a hospital ward experience higher mortality than those directly admitted to the ICU from an emergency department (64-67). This higher mortality may in part be attributable to progressive pneumonia, but "mis-triage" of patients with unrecognized severe pneumonia may be a contributing factor (64). It seems unlikely that physician judgment alone would be equivalent to physician judgment together with a severity tool to guide the site-of-care decision. We recommend the 2007 IDSA/ATS severe CAP criteria over other published scores, because they are composed of readily available severity parameters and are more accurate than the other scores described above.

\section{Research needed in this area.}

Controlled studies are needed to study the effectiveness and safety of using illness severity tools as decision aids to guide the intensity of treatment in adults hospitalized for pneumonia.

\section{Question 8: In the Outpatient Setting, Which Antibiotics Are Recommended for Empiric Treatment of CAP in Adults?}

\section{Recommendation.}

1. For healthy outpatient adults without comorbidities listed below or risk factors for antibiotic resistant pathogens, we recommend (Table 3 ):

- amoxicillin $1 \mathrm{~g}$ three times daily (strong recommendation, moderate quality of evidence), or

- doxycycline $100 \mathrm{mg}$ twice daily (conditional recommendation, low quality of evidence), or

- a macrolide (azithromycin $500 \mathrm{mg}$ on first day then $250 \mathrm{mg}$ daily or clarithromycin $500 \mathrm{mg}$ twice daily or clarithromycin extended release $1,000 \mathrm{mg}$ daily) only in areas with pneumococcal resistance to macrolides $<25 \%$ (conditional recommendation, moderate quality of evidence).

2. For outpatient adults with comorbidities such as chronic heart, lung, liver, or renal disease; diabetes mellitus; alcoholism; malignancy; or asplenia we recommend (in no particular order of preference) (Table 3):

- Combination therapy:

○ amoxicillin/clavulanate $500 \mathrm{mg} / 125$ mg three times daily, or amoxicillin/ clavulanate $875 \mathrm{mg} / 125 \mathrm{mg}$ twice daily, or 2,000 mg/125 mg twice daily, or a cephalosporin (cefpodoxime $200 \mathrm{mg}$ twice daily or cefuroxime $500 \mathrm{mg}$ twice daily); AND

○ macrolide (azithromycin $500 \mathrm{mg}$ on first day then $250 \mathrm{mg}$ daily, clarithromycin [500 mg twice daily or extended release $1,000 \mathrm{mg}$ once daily]) (strong recommendation, moderate quality of evidence for combination therapy), or doxycycline $100 \mathrm{mg}$ twice daily (conditional recommendation, low quality of evidence for combination therapy); OR

- Monotherapy:

- respiratory fluoroquinolone (levofloxacin $750 \mathrm{mg}$ daily, moxifloxacin $400 \mathrm{mg}$ daily, or gemifloxacin $320 \mathrm{mg}$ daily) (strong recommendation, moderate quality of evidence).

Summary of the evidence. RCTs of antibiotic treatment regimens for adults with CAP provide little evidence of either superiority or equivalence of one antibiotic regimen over another, because of small numbers and the rare occurrence of important outcomes such as mortality or treatment failure resulting in hospitalization. Several published trials included comparators that are no longer available (e.g., ketolides). This paucity of data was noted in a 2014 Cochrane review (68).

We identified 16 relevant RCTs comparing two antibiotic regimens for the treatment of outpatient CAP (69-84). Metaanalyses of each of these groups of studies revealed no differences in relevant outcomes between any of the compared regimens. Similar findings have been 
reported in a 2008 meta-analysis of antibiotic treatment for outpatient CAP (85).

The committee also considered whether to accept data regarding oral antibiotics given to inpatients with CAP. We believed that this evidence, albeit indirect, could be reasonably extended to outpatients, because inpatients are generally higher risk and more severely ill. As observational data suggest that inpatient and outpatient CAP are due to the same pathogens $(69,71-73$, 82), except for Legionella and gram-negative bacilli, which are rarely documented in outpatient settings, it seems reasonable that an antibiotic regimen that was effective for inpatients would be effective for outpatients.

Studies of high-dose oral amoxicillin have demonstrated efficacy for inpatients with CAP (86-88). Similarly, there is evidence supporting amoxicillin-clavulanic acid in outpatient CAP $(71,73)$ and inpatient CAP $(89,90)$.

There are limited data regarding oral doxycycline for pneumonia, mostly involving small numbers of patients (81). Intravenous doxycycline $100 \mathrm{mg}$ twice daily compared favorably to intravenous levofloxacin $500 \mathrm{mg}$ daily in 65 in patients with CAP (91). In an open-label randomized trial of intravenous doxycycline $100 \mathrm{mg}$ twice daily compared with standard antibiotics, doxycycline was associated with a quicker response and less change in antibiotics (92).

Rationale for the recommendation. Given the paucity of RCT data in the outpatient setting, the committee considered all available evidence. The data included the few RCTs of outpatient CAP, observational studies, RCTs of inpatient CAP treatment, antimicrobial resistance data from surveillance programs, and data regarding antibiotic-related adverse events.

For patients without comorbidities that increase the risk for poor outcomes, the panel recommended amoxicillin $1 \mathrm{~g}$ every 8 hours or doxycycline $100 \mathrm{mg}$ twice daily. The recommendation for amoxicillin was based on several studies that showed efficacy of this regimen for inpatient CAP despite presumed lack of coverage of this antibiotic for atypical organisms. This treatment also has a long track record of safety. The recommendation for doxycycline was based on limited clinical trial data, but a broad spectrum of action, including the most common relevant organisms. Some experts recommend that the first dose of oral doxycycline be $200 \mathrm{mg}$, to achieve adequate serum levels more rapidly. There are no data assessing whether such an approach is associated with improved outcomes.

In a departure from the prior CAP guidelines, the panel did not give a strong recommendation for routine use of a macrolide antibiotic as monotherapy for outpatient CAP, even in patients without comorbidities. This was based on studies of macrolide failures in patients with macrolide-resistant S. pneumoniae $(93,94)$, in combination with a macrolide resistance rate of $>30 \%$ among $S$. pneumoniae isolates in the United States, most of which is highlevel resistance (95). However, in settings where macrolide resistance is documented to be low and there are contraindications to alternative therapies, a macrolide as monotherapy is a treatment option.

Patients with comorbidities should receive broader-spectrum treatment for two reasons. First, such patients are likely more vulnerable to poor outcomes if the initial empiric antibiotic regimen is inadequate. Second, many such patients have risk factors for antibiotic resistance by virtue of previous contact with the healthcare system and/or prior antibiotic exposure (see Recommendation 10) and are therefore recommended to receive broader-spectrum therapy to ensure adequate coverage. In addition to $H$. influenzae and $M$. catarrhalis (both of which frequently produce $\beta$-lactamase), $S$. aureus and gram-negative bacilli are more common causes of CAP in patients with comorbidities, such as COPD.

Regimens recommended for patients with comorbidities include a $\beta$-lactam or cephalosporin in combination with either a macrolide or doxycycline. These combinations should effectively target macrolide- and doxycycline-resistant $S$. pneumoniae (as $\beta$-lactam resistance in $S$. pneumoniae remains less common), in addition to $\beta$-lactamase-producing strains of $H$. influenzae, many enteric gramnegative bacilli, most methicillinsusceptible $S$. aureus, and $M$. pneumoniae and $C$. pneumoniae. The monotherapies listed also are effective against most common bacterial pathogens.

Both sets of treatment recommendations contain multiple antibiotic options without specifying a preference order. The choice between these options requires a risk-benefit assessment for each individual patient, weighing local epidemiological data against specific risk factors that increase the risk of individual choices, such as documented $\beta$-lactam or macrolide allergy, cardiac arrhythmia (macrolides), vascular disease (fluoroquinolones), and history of infection with Clostridium difficile. In particular, despite the concern regarding adverse events associated with fluoroquinolones, the panel believed that fluoroquinolone therapy was justified for adults with comorbidities and CAP managed in the outpatient setting. Reasons included the performance of fluoroquinolones in numerous studies of outpatient CAP $(70,72,75,77,80,83)$ and inpatient CAP (see inpatient CAP section), the very low resistance rates in common bacterial causes of CAP, their coverage of both typical and atypical organisms, their oral bioavailability, the convenience of monotherapy, and the relative rarity of serious adverse events related to their use. However, there have been increasing reports of adverse events related to fluoroquinolone use as summarized on the U.S. Food and Drug Administration website (96).

Of note, we adopt the convention of prior guidelines to recommend that patients with recent exposure to one class of antibiotics recommended above receive treatment with antibiotics from a different class, given increased risk for bacterial resistance to the initial treatment regimen. We also highlight that although patients with significant risk factors for CAP due to MRSA or P. aeruginosa (see Recommendation 11) are uncommonly managed in the outpatient setting, these patients may require antibiotics that include coverage for these pathogens.

Research needed in this area. There is a need for head-to-head prospective RCTs of outpatient CAP treatment, comparing clinical outcomes, including treatment failure, need for subsequent visits, hospitalization, time to return to usual activities and adverse events. Furthermore, the prevalence of specific pathogens and their antimicrobial susceptibility patterns in outpatients with pneumonia should be monitored. Newer agents, including lefamulin and omadacycline, need further validation in the outpatient setting.

\section{Question 9: In the Inpatient Setting, Which Antibiotic Regimens Are Recommended for Empiric Treatment of CAP in Adults without Risk Factors for MRSA and $P$. aeruginosa?}

Recommendation 9.1. In inpatient adults with nonsevere CAP without risk factors for 
MRSA or P. aeruginosa (see Recommendation 11), we recommend the following empiric treatment regimens (in no order of preference) (Table 4):

- combination therapy with a $\beta$-lactam (ampicillin + sulbactam 1.5-3 g every $6 \mathrm{~h}$, cefotaxime $1-2 \mathrm{~g}$ every $8 \mathrm{~h}$, ceftriaxone 1-2 g daily, or ceftaroline $600 \mathrm{mg}$ every $12 \mathrm{~h}$ ) and a macrolide (azithromycin $500 \mathrm{mg}$ daily or clarithromycin $500 \mathrm{mg}$ twice daily) (strong recommendation, high quality of evidence), or

- monotherapy with a respiratory fluoroquinolone (levofloxacin $750 \mathrm{mg}$ daily, moxifloxacin $400 \mathrm{mg}$ daily) (strong recommendation, high quality of evidence).

A third option for adults with CAP who have contraindications to both macrolides and fluoroquinolones is:

- combination therapy with a $\beta$-lactam (ampicillin + sulbactam, cefotaxime, ceftaroline, or ceftriaxone, doses as above) and doxycycline $100 \mathrm{mg}$ twice daily (conditional recommendation, low quality of evidence).

Summary of the evidence. Most randomized controlled studies of hospitalized adults with CAP comparing $\beta$-lactam/macrolide therapy versus fluoroquinolone monotherapy were designed as noninferiority trials and had limited sample sizes (97-103). These data suggested that patients treated with $\beta$-lactam/macrolide therapy have similar clinical outcomes compared with those treated with fluoroquinolone monotherapy. A systematic review of 16 RCTs in 4,809 patients found fluoroquinolone monotherapy resulted in significantly fewer incidences of clinical failure, treatment discontinuation, and diarrhea than $\beta$-lactam/macrolide combination (104). However, mortality rates were low overall, and there were no significant differences in mortality between groups. Another systematic review of 20 experimental and observational studies in adults hospitalized with radiographically confirmed CAP, $\beta$-lactam plus macrolide combination therapy, or fluoroquinolone monotherapy were generally associated with lower mortality than $\beta$-lactam monotherapy (105). Therefore, the panel recommends a $\beta$-lactam (ampicillin plus sulbactam, cefotaxime, ceftaroline, or ceftriaxone) plus macrolide (azithromycin or clarithromycin) or monotherapy with a respiratory fluoroquinolone (levofloxacin, moxifloxacin) for the management of inpatients with nonsevere CAP. (Of note, azithromycin but not clarithromycin is available in parenteral formulation.) In choosing between these two options, clinicians should weigh the risks and benefits of the drugs, particularly in light of individual risk factors, such as a history of C. difficile infection or risk factors related to U.S. Food and Drug Administration warnings (96). The panel recommends using doxycycline as an alternative to a macrolide in combination with a $\beta$ lactam as a third option in the presence of documented allergies or contraindications to macrolides or fluoroquinolones or clinical failure on one of those agents. Of note, a newer member of the tetracycline class, omadacycline, was recently reported to be equivalent to moxifloxacin as monotherapy for adults with nonsevere CAP and is effective in the setting of tetracycline resistance (106). However, as this is a single published report and the safety information is less well established, the committee decided to not list this new agent as an alternative to the currently recommended treatment options.

The panel also considered $\beta$-lactam monotherapy as an option for inpatients with nonsevere CAP. An RCT in 580 patients with CAP could not rule out the possibility that $\beta$-lactam monotherapy was inferior to $\beta$-lactam/macrolide therapy for inpatients with CAP (107). Nie and colleagues identified several cohort $(n=4)$ and retrospective observational $(n=12)$ studies addressing this question and found that $\beta$-lactam/macrolide therapy reduced mortality in patients with CAP compared with patients treated with $\beta$-lactam monotherapy (108). Similarly, Horita and colleagues demonstrated that $\beta$-lactam/macrolide combinations may decrease all-cause death, but mainly for patients with severe CAP (109). Therefore, we suggest that $\beta$-lactam monotherapy should not be routinely used for inpatients with CAP over fluoroquinolone monotherapy or $\beta$-lactam/macrolide combination therapy.

Rationale for the recommendation. As summarized in Table 4, the empiric antibiotic coverage recommendations for patients hospitalized with CAP remain aligned to cover the most likely pathogens causing CAP. There is a paucity of RCTs to favor the recommendation of combination $\beta$-lactam plus macrolide versus monotherapy with a respiratory fluoroquinolone versus combined therapy with $\beta$-lactam plus doxycycline.

Research needed in this area. There is a need for higher-quality evidence in support of the use of combination therapy with a $\beta$-lactam and doxycycline. Given concerns over increasing drug resistance (macrolides) and safety issues (macrolides, fluoroquinolones), there is a need for research on new therapeutic agents for adults with CAP including omadacycline (see above) and lefamulin, a new pleuromutilin antibiotic that was recently demonstrated to be noninferior to moxifloxacin in hospitalized adult patients with CAP (110).

Recommendation 9.2. In inpatient adults with severe CAP (see Table 1) without risk factors for MRSA or $P$. aeruginosa, we recommend (Table 4) (note, specific agents and doses are the same as 9.1):

- a $\beta$-lactam plus a macrolide (strong recommendation, moderate quality of evidence); or

- a $\beta$-lactam plus a respiratory fluoroquinolone (strong recommendation, low quality of evidence).

Summary of the evidence. In the absence of RCTs evaluating therapeutic alternatives in severe CAP, the evidence is from observational studies that used different definitions of illness severity to address this question. Sligl and colleagues found in a meta-analysis of observational studies with almost 10,000 critically ill patients with CAP that macrolidecontaining therapies (often in combination with a $\beta$-lactam) were associated with a significant mortality reduction $(18 \%$ relative risk, $3 \%$ absolute risk) compared with non-macrolide-containing therapies (111). A mortality benefit from macrolides has been observed mainly in cohorts with a large number of patients with severe CAP. In a systematic review, Vardakas and colleagues compared a $\beta$-lactam/fluoroquinolone versus a $\beta$-lactam/macrolide combination for the treatment of patients with CAP (112). The authors found 17 observational studies and no RCTs addressing this comparison. The combination of $\beta$-lactam/fluoroquinolone 
therapy was associated with higher mortality than $\beta$-lactam/macrolide combination therapy, but the overall quality of the studies was judged to be low, precluding a definitive recommendation (112).

Rationale for the recommendation. In the absence of data from clinical trials demonstrating the superiority of any specific regimen for patients with severe CAP, the committee considered epidemiological data for severe CAP pathogens and observational studies comparing different regimens. As a result, we recommend that combination therapy with a $\beta$-lactam plus a macrolide or a $\beta$ lactam plus a respiratory fluoroquinolone should be the treatment of choice for patients with severe CAP. Both fluoroquinolone monotherapy and the combination of $\beta$-lactam plus doxycycline have not been well studied in severe CAP and are not recommended as empiric therapy for adults with severe CAP.

Research needed in this area. Future well-designed RCTs should focus on therapies for patients at highest risk of death with severe pneumonia, as these are needed to assess the benefits and risks of combination $\beta$-lactam and macrolide therapy compared with $\beta$-lactam and respiratory fluoroquinolone therapy. Studies of fluoroquinolone monotherapy in severe CAP are also needed.

\section{Question 10: In the Inpatient Setting, Should Patients with Suspected Aspiration Pneumonia Receive Additional Anaerobic Coverage beyond Standard Empiric Treatment for CAP?}

Recommendation. We suggest not routinely adding anaerobic coverage for suspected aspiration pneumonia unless lung abscess or empyema is suspected (conditional recommendation, very low quality of evidence).

Summary of the evidence. Aspiration is a common event, and as many as half of all adults aspirate during sleep (113). As a result, the true rate of aspiration pneumonia is difficult to quantify, and there is no definition that separates patients with aspiration pneumonia from all others diagnosed with pneumonia. Some have estimated that $5 \%$ to $15 \%$ of pneumonia hospitalizations are associated with aspiration (114). Rates are higher in populations admitted from nursing homes or extended care facilities (115).

Patients who aspirate gastric contents are considered to have aspiration pneumonitis. Many of these patients have resolution of symptoms within 24 to 48 hours and require only supportive treatment, without antibiotics (116).

Studies evaluating the microbiology of patients with aspiration pneumonia in the 1970s showed high rates of isolation of anaerobic organisms $(117,118)$; however, these studies often used trans-tracheal sampling and evaluated patients late in their disease course, two factors that may have contributed to a higher likelihood of identifying anaerobic organisms (114). Several studies of acute aspiration events in hospitalized patients have suggested that anaerobic bacteria do not play a major role in etiology (119-121).

With increasing rates of $C$. difficile infections (frequently associated with use of clindamycin), the question of adding empiric anaerobic coverage (clindamycin or $\beta$-lactam $/ \beta$-lactamase inhibitors) in addition to routine CAP treatment in patients with suspected aspiration is an important one. However, there are no clinical trials comparing treatment regimens with and without anaerobic coverage for patients hospitalized with suspected aspiration. Most recent studies are small, retrospective, and provide only observational data on microbiologic patterns and treatment regimens for patients hospitalized with suspected aspiration pneumonia.

Rationale for the recommendation. Although older studies of patients with aspiration pneumonia showed high isolation rates of anaerobic organisms, more recent studies have shown that anaerobes are uncommon in patients hospitalized with suspected aspiration $(119,120)$. Increasing prevalence of antibiotic-resistant pathogens and complications of antibiotic use highlight the need for a treatment approach that avoids unnecessary use of antibiotics.

Research needed in this area. Clinical trials evaluating diagnostic and treatment strategies in patients with suspected aspiration are needed, especially in terms of the ability to distinguish micro- and macroaspiration events that lead to lower respiratory tract infection from those that do not result in infection.

\section{Question 11: In the Inpatient Setting, Should Adults with CAP and Risk Factors for MRSA or $P$. aeruginosa $\mathrm{Be}$ Treated with Extended-Spectrum Antibiotic Therapy Instead of Standard CAP Regimens?}

Recommendation. We recommend abandoning use of the prior categorization of healthcare-associated pneumonia (HCAP) to guide selection of extended antibiotic coverage in adults with CAP (strong recommendation, moderate quality of evidence).

We recommend clinicians only cover empirically for MRSA or $P$. aeruginosa in adults with CAP if locally validated risk factors for either pathogen are present (strong recommendation, moderate quality of evidence). Empiric treatment options for MRSA include vancomycin $(15 \mathrm{mg} / \mathrm{kg}$ every $12 \mathrm{~h}$, adjust based on levels) or linezolid (600 mg every $12 \mathrm{~h}$ ). Empiric treatment options for $P$. aeruginosa include piperacillin-tazobactam ( $4.5 \mathrm{~g}$ every $6 \mathrm{~h})$, cefepime ( 2 g every $8 \mathrm{~h}$ ), ceftazidime ( $2 \mathrm{~g}$ every $8 \mathrm{~h})$, aztreonam ( 2 g every $8 \mathrm{~h})$, meropenem ( 1 g every $8 \mathrm{~h}$ ), or imipenem (500 mg every $6 \mathrm{~h}$ ).

If clinicians are currently covering empirically for MRSA or $P$. aeruginosa in adults with CAP on the basis of published risk factors but do not have local etiological data, we recommend continuing empiric coverage while obtaining culture data to establish if these pathogens are present to justify continued treatment for these pathogens after the first few days of empiric treatment (strong recommendation, low quality of evidence).

Summary of the evidence. HCAP, as a distinct clinical entity warranting unique antibiotic treatment, was incorporated into the 2005 ATS/IDSA guidelines for management of hospital-acquired and ventilator-associated pneumonia (122). HCAP was defined for those patients who had any one of several potential risk factors for antibiotic-resistant pathogens, including residence in a nursing home and other long-term care facilities, hospitalization for $\geqslant 2$ days in the last 90 days, receipt of home infusion therapy, chronic dialysis, home wound care, or a family member with a known antibiotic-resistant pathogen. The introduction of HCAP was based on studies identifying a higher prevalence of 
pathogens that are not susceptible to standard first-line antibiotic therapy, in particular MRSA and $P$. aeruginosa, in some subsets of patients with CAP (123). Since then, many studies have demonstrated that the factors used to define HCAP do not predict high prevalence of antibiotic-resistant pathogens in most settings. Moreover, a significant increased use of broad-spectrum antibiotics (especially vancomycin and antipseudomonal $\beta$-lactams) has resulted, without any apparent improvement in patient outcomes (124-133).

Studies have identified risk factors for antibiotic-resistant pathogens, and in some cases the risk factors are distinct for MRSA versus $P$. aeruginosa (134-154). However, most of these individual risk factors are weakly associated with these pathogens. The most consistently strong individual risk factors for respiratory infection with MRSA or $P$. aeruginosa are prior isolation of these organisms, especially from the respiratory tract, and/or recent hospitalization and exposure to parenteral antibiotics $(134,155$, 156). Therefore, we have highlighted these individual risk factors to help guide initial microbiological testing and empiric coverage for these pathogens.

Unfortunately, no validated scoring systems exist to identify patients with MRSA or $P$. aeruginosa with sufficiently high positive predictive value to determine the need for empiric extended-spectrum antibiotic treatment. Scoring system development and validation are complicated by varying prevalence of MRSA and $P$. aeruginosa in different study populations. Moreover, no scoring system has been demonstrated to improve patient outcomes or reduce overuse of broad-spectrum antibiotics.

Although there is limited evidence to support the use of a specific set of risk factors to identify patients with sufficiently high risk of MRSA or $P$. aeruginosa to warrant extended-spectrum therapy, a stronger evidence base guides deescalation of therapy after extendedspectrum therapy is initially prescribed. Although no randomized prospective studies have been reported, recent observational (157) and retrospective (158-161) studies in patients with CAP provide strong evidence that deescalation of antibiotic therapy at 48 hours in accord with microbiological results that do not yield MRSA or P. aeruginosa is safe and reduces duration of antibiotic treatment, length of hospitalization, and complications of broad-spectrum therapy. These results are reinforced by retrospective (162) and prospective and randomized but not blinded (163) studies of patients with severe sepsis, the majority of whom had pneumonia, as well as by a recent meta-analysis of deescalation in adults with sepsis (164).

We propose that clinicians need to obtain local data on whether MRSA or $P$. aeruginosa is prevalent in patients with CAP and what the risk factors for infection are at a local (i.e., hospital or catchment area) level. We refer to this process as "local validation." This recommendation is based on the absence of high-quality outcome studies, the very low prevalence of MRSA or $P$. aeruginosa in most centers, and significant increased use of anti-MRSA and antipseudomonal antibiotics for treatment of CAP $(142,155,165)$. Although we acknowledge that centers may not currently have local prevalence data, adopting the recommendations for culture of sputum and blood when risk factors for MRSA or $P$. aeruginosa are present will enable clinicians to generate these local data over time. We recommend analyzing the frequency of MRSA or $P$. aeruginosa as a CAP pathogen relative to the number of all cases of CAP, not just those for whom cultures are sent. Finally, routine cultures in patients empirically treated for MRSA or $P$. aeruginosa allow deescalation to standard CAP therapy if cultures do not reveal a drug-resistant pathogen and the patient is clinically improving at 48 hours.

Rationale for the recommendation. Our approach to treating inpatient adults with CAP is summarized in Table 4. Our recommendation against using the former category of HCAP as a basis for selecting extended-spectrum therapy is based on high-quality studies of patient outcomes. Although we understand that clinicians would prefer a simple rule that does not require incorporating site-specific data, the current evidence does not permit endorsement of a simple and accurate rule to determine which patients with CAP should be covered for MRSA and/or $P$. aeruginosa. However, the alternative approach to MRSA and $P$. aeruginosa that we propose as a replacement is not based on high-quality studies, because such studies do not exist. The lack of adequate outcome data and marked variation between sites in prevalence of MRSA and
$P$. aeruginosa make generalizing any findings extremely difficult. We hope that future research will improve our understanding of this challenging clinical problem.

Our first principle was to maintain the distinction between severe and nonsevere pneumonia as per prior guidelines, because the risk of inadequate empiric antibiotic therapy is much greater in severe CAP. As noted previously, severity is defined by the degree of physiological impairment, as classified by the IDSA/ATS 2007 criteria.

The second principle was that there is sufficient evidence that prior identification of MRSA or P. aeruginosa in the respiratory tract within the prior year predicts a very high risk of these pathogens being identified in patients presenting with CAP $(139,141,143,150,155,165)$, and therefore these were sufficient indications to recommend blood and sputum cultures and empiric therapy for these pathogens in patients with CAP in addition to coverage for standard CAP pathogens, with deescalation at 48 hours if cultures are negative. We endorse the empiric treatment recommendations for MRSA and $P$. aeruginosa provided by the 2016 Clinical Practice Guideline from IDSA and ATS for the management of adults with hospitalacquired and ventilator-associated pneumonia (166).

The major additional risk factors for MRSA and P. aeruginosa identified in the literature are hospitalization and parenteral antibiotic exposure in the last 90 days (136-138, 140, 142-151, 153). In patients with recent hospitalization and exposure to parenteral antibiotics, we recommend microbiological testing without empiric extended-spectrum therapy for treatment of nonsevere CAP and microbiological testing with extended-spectrum empiric therapy in addition to coverage for standard CAP pathogens for treatment of severe CAP, with deescalation at 48 hours if cultures are negative and the patient is improving.

The data supporting rapid MRSA nasal testing are robust $(167,168)$, and treatment for MRSA pneumonia can generally be withheld when the nasal swab is negative, especially in nonsevere CAP. However, the positive predictive value is not as high; therefore, when the nasal swab is positive, coverage for MRSA pneumonia should generally be initiated, but blood and sputum cultures should be sent and therapy deescalated if cultures are negative. However, this latter strategy of deescalation 
in the face of a positive nasal swab will vary depending on the severity of CAP and the local prevalence of MRSA as a pathogen.

\section{Question 12: In the Inpatient Setting, Should Adults with CAP Be Treated with Corticosteroids?}

\section{Recommendation. We recommend not} routinely using corticosteroids in adults with nonsevere CAP (strong recommendation, high quality of evidence).

We suggest not routinely using corticosteroids in adults with severe CAP (conditional recommendation, moderate quality of evidence).

We suggest not routinely using corticosteroids in adults with severe influenza pneumonia (conditional recommendation, low quality of evidence).

We endorse the Surviving Sepsis Campaign recommendations on the use of corticosteroids in patients with CAP and refractory septic shock (169).

Summary of the evidence. Two randomized controlled studies of corticosteroids used for treatment of CAP have shown significant reductions in mortality, length of stay, and/or organ failure. The first study found a large magnitude of mortality benefit that has not been replicated in other studies, raising concerns that the results overestimated the true effect (170). In the second study, there were baseline differences in renal function between groups (171). Other RCTs of corticosteroids in the treatment of CAP have not shown significant differences in clinically important endpoints. Differences have been observed in the time to resolution of fever and other features of clinical stability, but these have not translated into differences in mortality, length of stay, or organ failure $(172,173)$.

Some $(174,175)$, but not all $(176,177)$ meta-analyses of published corticosteroid studies have shown a mortality benefit in patients with severe CAP, although no consistent definition of disease severity was used. Side effects of corticosteroids (on the order of $240 \mathrm{mg}$ of hydrocortisone per day) include significant increases in hyperglycemia requiring therapy and possible higher secondary infection rates $(178,179)$. No reported study has shown excess mortality in the corticosteroidtreated group.

In pneumonia due to influenza, a metaanalysis (180) of predominantly small retrospective studies suggests that mortality may be increased in patients who receive corticosteroids. This finding might reflect the importance of innate immunity in defense against influenza as opposed to bacterial pneumonia.

Rationale for the recommendation. There are no data suggesting benefit of corticosteroids in patients with nonsevere CAP with respect to mortality or organ failure and only limited data in patients with severe CAP. The risk of corticosteroids in the dose range up to $240 \mathrm{mg}$ of hydrocortisone equivalent per day for a maximum of 7 days is predominantly hyperglycemia, although rehospitalization rates may also be higher (176), and more general concerns about greater complications in the following 30 to 90 days have been raised (179). At least one large trial (clinicaltrials.gov NCT01283009) has been completed but not reported and may further inform which subgroups of patients benefit from steroids. We also endorse the Surviving Sepsis Campaign recommendations on the use of steroids in patients with septic shock refractory to adequate fluid resuscitation and vasopressor support (169).

Of note, there is no intent that our recommendations would override clinically appropriate use of steroids for comorbid diseases, such as chronic obstructive pulmonary disease, asthma, and autoimmune diseases, where corticosteroids are supported as a component of treatment.

Research needed in this area. Large, multicenter, randomized trials with welldefined inclusion and exclusion criteria and measurement of multiple relevant clinical outcomes are needed to define the subsets of patients (if any) who benefit or are potentially harmed from corticosteroid therapy. The trial should also make extensive efforts to define causative pathogens, to define whether there are clear pathogen-specific indications or contraindications for corticosteroid therapy (especially disease due to $S$. pneumoniae and influenza).

\section{Question 13: In Adults with CAP Who Test Positive for Influenza, Should the Treatment Regimen Include Antiviral Therapy?}

Recommendation. We recommend that antiinfluenza treatment, such as oseltamivir, be prescribed for adults with CAP who test positive for influenza in the inpatient setting, independent of duration of illness before diagnosis (strong recommendation, moderate quality of evidence).

We suggest that antiinfluenza treatment be prescribed for adults with CAP who test positive for influenza in the outpatient setting, independent of duration of illness before diagnosis (conditional recommendation, low quality of evidence).

Summary of the evidence. No clinical trials have evaluated the effect of treatment with antiinfluenza agents in adults with influenza pneumonia, and data are lacking on the benefits of using antiinfluenza agents in the outpatient setting for patients with CAP who test positive for influenza virus. Several observational studies suggest that treatment with oseltamivir is associated with reduced risk of death in patients hospitalized for CAP who test positive for influenza virus $(181,182)$. Treatment within 2 days of symptom onset or hospitalization may result in the best outcomes $(183,184)$, although there may be benefits up to 4 or 5 days after symptoms begin $(181,185)$.

The use of antiinfluenza agents in the outpatient setting reduces duration of symptoms and the likelihood of lower respiratory tract complications among patients with influenza (186), with most benefit if therapy is received within 48 hours after onset of symptoms (187).

Rationale for the recommendation. For inpatients, a substantial body of observational evidence suggests that giving antiinfluenza agents reduces mortality risk in adults with influenza infection. Although benefits are strongest when therapy is started within 48 hours of symptom onset, studies also support starting later (185). These data underlie our strong recommendation for using antiinfluenza agents for patients with CAP and influenza in the inpatient setting, consistent with the recently published IDSA Influenza Clinical Practice Guideline (33).

Although we did not identify studies that specifically evaluated antiinfluenza agents for treating outpatients with CAP who test positive for influenza, we make the same recommendation as for inpatients, on the basis of the inpatient data and on outpatient data showing better time to resolution of symptoms and prevention of hospitalization among those with influenza but without pneumonia. Our recommendations are consistent with the 
IDSA influenza guidelines, which were recently released (33).

\section{Research needed in this area.}

Randomized controlled studies are needed to support the recommendation for use of antiinfluenza agents to treat for influenza pneumonia in the outpatient setting. In particular, knowing whether therapy is valuable when started more the 48 hours after symptom onset would help guide clinical decision-making.

\section{Question 14: In Adults with CAP Who Test Positive for Influenza, Should the Treatment Regimen Include Antibacterial Therapy?}

Recommendation. We recommend that standard antibacterial treatment be initially prescribed for adults with clinical and radiographic evidence of CAP who test positive for influenza in the inpatient and outpatient settings (strong recommendation, low quality of evidence).

Summary of the evidence. Bacterial pneumonia can occur concurrently with influenza virus infection or present later as a worsening of symptoms in patients who were recovering from their primary influenza virus infection. As many as $10 \%$ of patients hospitalized for influenza and bacterial pneumonia die as a result of their infection (188). An autopsy series from the $2009 \mathrm{H} 1 \mathrm{~N} 1$ influenza pandemic found evidence of bacterial coinfection in about $30 \%$ of deaths (189).

$S$. aureus is one of the most common bacterial infections associated with influenza pneumonia, followed by $S$. pneumoniae, $H$. influenzae, and group A Streptococcus; other bacteria have also been implicated (188, 190-192). Given this spectrum of pathogens, appropriate agents for initial therapy include the same agents generally recommended for CAP. Risk factors and need for empiric coverage for MRSA would follow the guidelines included earlier in this document. Rapidly progressive severe pneumonia with MRSA has been described in previously healthy young patients, particularly in the setting of prior influenza; however, it is typically readily identified in the nares or sputum and should be identified by following the recommendations of earlier recommendations in this guideline.

Rationale for the recommendation. The recommendation to routinely prescribe antibacterial agents in patients with influenza virus infection and pneumonia was based on evidence suggesting that bacterial coinfections are a common and serious complication of influenza, as well as the inability to exclude the presence of bacterial coinfection in a patient with CAP who has a positive test for influenza virus. Although low levels of biomarkers such as procalcitonin decrease the likelihood that patients have bacterial infections, these biomarkers do not completely rule out bacterial pneumonia in an individual patient with sufficient accuracy to justify initially withholding antibiotic therapy, especially among patients with severe CAP $(37,38,193)$. We have provided a strong recommendation because of the significant risk of treatment failure in delaying appropriate antibacterial therapy in patients with CAP. However in patients with CAP, a positive influenza test, no evidence of a bacterial pathogen (including a low procalcitonin level), and early clinical stability, consideration could be given to earlier discontinuation of antibiotic treatment at 48 to 72 hours.

Research needed in this area. Randomized controlled studies are needed to establish whether antibacterial therapy can be stopped at 48 hours for patients with CAP who test positive for influenza and have no biomarker (e.g., procalcitonin) or microbiological evidence of a concurrent bacterial infection.

\section{Question 15: In Outpatient and Inpatient Adults with CAP Who Are Improving, What Is the Appropriate Duration of Antibiotic Treatment?}

Recommendation. We recommend that the duration of antibiotic therapy should be guided by a validated measure of clinical stability (resolution of vital sign abnormalities [heart rate, respiratory rate, blood pressure, oxygen saturation, and temperature], ability to eat, and normal mentation), and antibiotic therapy should be continued until the patient achieves stability and for no less than a total of 5 days (strong recommendation, moderate quality of evidence).

Summary of the evidence. A small number of randomized trials address the appropriate duration of antibiotic therapy in CAP, and randomized placebo-controlled trials of high quality are mostly limited to the inpatient setting. In these trials, no difference was observed between 5 additional days of oral amoxicillin compared with placebo in patients who had clinically improved on 3 days of intravenous amoxicillin (194), or between 2 days of intravenous cefuroxime followed by 5 days versus 8 days of oral cefuroxime (195). Similar results were obtained with 5 days of levofloxacin $750 \mathrm{mg}$ daily compared with 10 days of levofloxacin $500 \mathrm{mg}$ daily (196) and 5 days of intravenous ceftriaxone compared with 10 days (197). Several recent metaanalyses similarly demonstrate the efficacy of shorter courses of antibiotic therapy of 5 to 7 days (198-200).

Several studies have demonstrated that the duration of antibiotic therapy can be reduced in patients with CAP with the use of a procalcitonin-guided pathway and serial procalcitonin measurement compared with conventional care, but in most cases the average length of treatment was greatly in excess of current U.S. standards of practice as well as the recommendations of these current guidelines. Concern has also been raised that procalcitonin levels may not be elevated when there is concurrent viral and bacterial infection $(201,202)$ or with important pathogens such as Legionella and Mycoplasma spp $(37,201,203)$. Serial procalcitonin measurement is therefore likely to be useful primarily in settings where the average length of stay for patients with CAP exceeds normal practice (e.g., 5-7 d).

It is recognized that some patients do not respond to a standard duration of therapy. A variety of criteria for determining clinical improvement have been developed for patients with CAP and validated in clinical trials, including resolution of vital sign abnormalities (heart rate, respiratory rate, blood pressure, oxygen saturation, and temperature), ability to eat, and normal mentation (204). Failure to achieve clinical stability within 5 days is associated with higher mortality and worse clinical outcomes (205-207). Such failure should prompt assessment for a pathogen resistant to the current therapy and/or complications of pneumonia (e.g., empyema or lung abscess) or for an alternative source of infection and/or inflammatory response $(208,209)$. When assessment of clinical stability has been introduced into clinical practice, patients have shorter durations of antibiotic therapy without adverse impact on outcome (210). All clinicians should therefore use an assessment of clinical stability as part of routine care of patients with CAP.

Longer courses of antibiotic therapy are recommended for 1) pneumonia 
complicated by meningitis, endocarditis, and other deep-seated infection; or 2) infection with other, less-common pathogens not covered in these guidelines (e.g., Burkholderia pseudomallei, Mycobacterium tuberculosis or endemic fungi).

\section{Rationale for the recommendation.}

As recent data supporting antibiotic administration for $<5$ days are scant, on a risk-benefit basis we recommend treating for a minimum of 5 days, even if the patient has reached clinical stability before 5 days. As most patients will achieve clinical stability within the first 48 to 72 hours, a total duration of therapy of 5 days will be appropriate for most patients. In switching from parenteral to oral antibiotics, either the same agent or the same drug class should be used.

We acknowledge that most studies in support of 5 days of antibiotic therapy include patients without severe CAP, but we believe these results apply to patients with severe CAP and without infectious complications. We believe that the duration of therapy for CAP due to suspected or proven MRSA or P. aeruginosa should be 7 days, in agreement with the recent hospitalacquired pneumonia and ventilatorassociated pneumonia guidelines (166).

Research needed in this area. Controlled studies are needed to establish the duration of antibiotic therapy for adults with complications of CAP, including empyema, and adults with prolonged time to achieving clinical stability.

\section{Question 16: In Adults with CAP Who Are Improving, Should Follow-up Chest Imaging Be Obtained?}

Recommendation. In adults with CAP whose symptoms have resolved within 5 to 7 days, we suggest not routinely obtaining follow-up chest imaging (conditional recommendation, low quality of evidence).

Summary of the evidence. There are limited data on the clinical usefulness of reimaging patients with pneumonia. Most available data have evaluated whether reimaging patients detects lung malignancy not recognized at the time of treatment for pneumonia. Reported rates of malignancy in patients recovering from CAP range from $1.3 \%$ to $4 \%$ (211-214). When unsuspected nonmaligant pathology is included, the rate of abnormal findings may reach $5 \%$.

Almost all patients with malignancy in reported series were smokers or ex-smokers. One longer-term study found $9.2 \%$ of CAP survivors in the Veterans Affairs system (with a predominantly male population and high smoking prevalence) had a new diagnosis of cancer, with a mean time to diagnosis of 297 days. However, only 27\% were diagnosed within 90 days of discharge from hospital, suggesting the yield of routine follow-up post discharge would be low (215).

Rationale for the recommendation. Available data suggest the positive yield from repeat imaging ranges from $0.2 \%$ to $5.0 \%$; however many patients with new abnormalities in these studies meet criteria for lung cancer screening among current or past smokers (216).

Research needed in this area. Further research may clarify subgroups of patients who may benefit from further radiological assessment after initial therapy for pneumonia.

\section{Conclusions}

Recommendations to help clinicians optimize therapy for their patients with CAP have been revised in light of new data. Methods of quality improvement are critical to the implementation of guideline recommendations. It remains disappointing how few key clinical questions have been studied adequately enough to allow for strong recommendations regarding the standard of care. We hope that the research priorities outlined in this document will prompt new investigations addressing key knowledge gaps.

Despite substantial concern over the rise of antibiotic-resistant pathogens, most patients with CAP can be adequately treated with regimens that have been used for multiple decades. It is also true that the subset of patients with CAP who have significant comorbidities and frequent contact with healthcare settings and antibiotics is increasing, and, in some settings, the rates of infection with MRSA or $P$. aeruginosa are high enough to warrant empiric treatment.
Unfortunately, microbiological testing has yet to deliver fast, accurate, and affordable testing that results in proven benefit for patients with CAP in terms of more rapid delivery of targeted therapy or safe deescalation of unnecessary therapy. Exceptions include rapid testing for MRSA and influenza. Until we have such widely available (and affordable) tests, therapy for many or most patients with CAP will remain empiric. Therefore, clinicians need to be aware of the spectrum of local pathogens, especially if they care for patients at a center where infection with antibiotic-resistant pathogens such as MRSA and $P$. aeruginosa are more common.

A difference between this guideline and previous ones is that we have significantly increased the proportion of patients in whom we recommend routinely obtaining respiratory tract samples for microbiologic studies. This decision is largely based on a desire to correct the overuse of anti-MRSA and antipseudomonal therapy that has occurred since the introduction of the HCAP classification (which we recommend abandoning) rather than high-quality evidence. We expect this change will generate significant research to prove or disprove the value of this approach. As it is not possible to create a "one size fits all" schema for empiric therapy for CAP, clinicians must validate any approach taking into account their local spectrum and frequency of resistant pathogens, which is another driver for recommending increased testing. We similarly expect our move against endorsing monotherapy with macrolides, which is based on population resistance data rather than high-quality clinical studies, will generate future outcomes studies comparing different treatment strategies.

We hope that clinicians and researchers will find this guideline useful, but the recommendations included here do not obviate the need for clinical assessment and knowledge to ensure each individual patient receives appropriate and timely care. However, this guideline delineates minimum clinical standards that are achievable and will help drive the best patient outcomes on the basis of currently available data. 
This clinical practice guideline was prepared by an ATS/IDSA ad hoc committee on community-acquired pneumonia in adults.

\section{Members of the committee are as follows:}

Joshua P. Metlay, M.D., Ph.D. $(\text { Co-Chair })^{1,2}$

Grant W. Waterer, M.B. B.S., Ph.D. $(\text { Co-Chair })^{3}$

Antonio Anzueto, M.D., ${ }^{4,5}$

Jan Brozek, M.D., Ph.D. ${ }^{6 *}$

Kristina Crothers, M.D. ${ }^{7,8}$

Laura A. Cooley, M.D. ${ }^{9}$

Nathan C. Dean, M.D. ${ }^{10,11}$

Michael J. Fine, M.D., M.Sc. ${ }^{12,13}$

SCOTT A. Flanders, M.D. ${ }^{14}$

Marie R. Griffin, M.D., M.P.H. ${ }^{15}$

AnN C. Long, M.D., M.S. ${ }^{8 \star}$

MARK L. MetersKY, M.D. ${ }^{16}$

Daniel M. Musher, M.D. ${ }^{17,18}$

Marcos I. Restrepo, M.D., M.Sc., Ph.D. ${ }^{4,5}$

Cynthia G. Whitney, M.D., M.P.H. ${ }^{9}$

\section{*Methodologist.}

${ }^{1}$ Massachusetts General Hospital, Boston, Massachusetts; ${ }^{2}$ Harvard Medical School, Boston, Massachusetts; ${ }^{3}$ Royal Perth Hospital and University of Western Australia, Perth, Australia; ${ }^{4}$ South Texas Veterans Healthcare System, San Antonio, Texas; ${ }^{5}$ University of Texas Health San Antonio, San Antonio, Texas; ${ }^{6}$ McMaster University, Hamilton, Ontario, Canada; ${ }^{7}$ VA Puget Sound Health Care System, Seattle, Washington; ${ }^{8}$ University of Washington, Seattle, Washington;

${ }^{9}$ Respiratory Diseases Branch, Centers for Disease Control and Prevention, Atlanta, Georgia; ${ }^{10}$ Intermountain Medical Center, Salt Lake City, Utah; ${ }^{11}$ University of Utah, Salt Lake City, Utah; ${ }^{12}$ VA Pittsburgh Medical Center, Pittsburgh, Pennsylvania; ${ }^{13}$ University of Pittsburgh, Pittsburgh, Pennsylvania; ${ }^{14}$ University of Michigan, Ann Arbor, Michigan; ${ }^{15}$ Vanderbilt University, Nashville, Tennessee; ${ }^{16}$ University of Connecticut School of Medicine, Farmington, Connecticut; ${ }^{17}$ Michael E. DeBakey VA Medical Center, Houston, Texas; and ${ }^{18}$ Baylor College of Medicine, Houston, Texas

\section{Author Disclosures: A.A. served as} a consultant for AstraZeneca, Bayer Boehringer Ingelheim, GlaxoSmithKline, Novartis, Pfizer, and Sunovion; served on an advisory committee for AstraZeneca, Forest, and Novartis; served on a data safety and monitoring board for Bayer; and received research support from GlaxoSmithKline. N.C.D. served as a consultant for Cerexa; served on a data safety and monitoring board for Contrafect and Theravance; and served on an advisory committee for Cempra and Paratek. S.A.F. received research support from the Blue Cross Blue Shield of Michigan; received personal fees for expert testimony related to the practice of hospital medicine; and received royalties from Wiley Publishing A.C.L. has ownership or investment interest with Aurora Cannabis, Canopy Growth, and Cronos Group. M.L.M. received research support from Gilead, Insmed, Multiclonal Therapeutics, and Pharmaxis; served as a consultant for Aradigm, Arsanis, Bayer, Insmed, International Biophysics, Savara, Shionogi, and various law firms; served as a consultant for EBSCO as a reviewer for DynaMed, a decision support tool; and served on an advisory committee and as a consultant for Grifols. J.P.M., G.W., J.B., K.C., L.A.C., M.J.F., M.R.G., D.M.M., M.I.R., and C.G.W. reported no relevant commercial relationships.

\section{References}

1. Mandell LA, Wunderink RG, Anzueto A, Bartlett JG, Campbell GD, Dean NC, et al.; Infectious Diseases Society of America; American Thoracic Society. Infectious Diseases Society of America/American Thoracic Society consensus guidelines on the management of communityacquired pneumonia in adults. Clin Infect Dis 2007;44:S27-S72.

2. Guyatt GH, Oxman AD, Kunz R, Atkins D, Brozek J, Vist G, et al. GRADE guidelines: 2. Framing the question and deciding on important outcomes. J Clin Epidemiol 2011;64:395-400.

3. Metlay JP, Kapoor WN, Fine MJ. Does this patient have communityacquired pneumonia? Diagnosing pneumonia by history and physical examination. JAMA 1997;278:1440-1445.

4. Sato T, Aoshima M, Ohmagari N, Tada H, Chohnabayashi N. Usefulness of sputum Gram staining in community-acquired pneumonia [in Japanese]. Nihon Kokyuki Gakkai Zasshi 2002;40:558-563.

5. Shariatzadeh MR, Marrie TJ. Does sputum culture affect the management and/or outcome of community-acquired pneumonia? East Mediterr Health J 2009;15:792-799.

6. Signori LG, Ferreira MW, Vieira LC, Muller KR, Mattos WL. Sputum examination in the clinical management of community-acquired pneumonia [in Portuguese]. J Bras Pneumol 2008;34:152-158.

7. Uematsu $H$, Hashimoto $H$, Iwamoto $T$, Horiguchi $H$, Yasunaga $H$. Impact of guideline-concordant microbiological testing on outcomes of pneumonia. Int J Qual Health Care 2014;26:100-107.

8. Lidman C, Burman LG, Lagergren A, Ortqvist A. Limited value of routine microbiological diagnostics in patients hospitalized for communityacquired pneumonia. Scand J Infect Dis 2002;34:873-879.

9. Sanyal S, Smith PR, Saha AC, Gupta S, Berkowitz L, Homel P. Initial microbiologic studies did not affect outcome in adults hospitalized with community-acquired pneumonia. Am J Respir Crit Care Med 1999;160:346-348.

10. van der Eerden MM, Vlaspolder F, de Graaff CS, Groot T, Bronsveld W, Jansen HM, et al. Comparison between pathogen directed antibiotic treatment and empirical broad spectrum antibiotic treatment in patients with community acquired pneumonia: a prospective randomised study. Thorax 2005;60:672-678.
11. Ewig S, Torres A, Angeles Marcos M, Angrill J, Rañó A, de Roux A, et al. Factors associated with unknown aetiology in patients with community-acquired pneumonia. Eur Respir J 2002;20: 1254-1262.

12. Ewig S, Schlochtermeier M, Göke N, Niederman MS. Applying sputum as a diagnostic tool in pneumonia: limited yield, minimal impact on treatment decisions. Chest 2002;121:1486-1492.

13. García-Vázquez E, Marcos MA, Mensa J, de Roux A, Puig J, Font C, et al. Assessment of the usefulness of sputum culture for diagnosis of community-acquired pneumonia using the PORT predictive scoring system. Arch Intern Med 2004;164:1807-1811.

14. Lévy M, Dromer F, Brion N, Leturdu F, Carbon C. Community-acquired pneumonia: importance of initial noninvasive bacteriologic and radiographic investigations. Chest 1988;93:43-48.

15. Miyashita N, Shimizu H, Ouchi K, Kawasaki K, Kawai Y, Obase Y, et al. Assessment of the usefulness of sputum Gram stain and culture for diagnosis of community-acquired pneumonia requiring hospitalization. Med Sci Monit 2008;14:CR171-CR176.

16. Rosón B, Carratalà J, Verdaguer R, Dorca J, Manresa F, Gudiol F. Prospective study of the usefulness of sputum Gram stain in the initial approach to community-acquired pneumonia requiring hospitalization. Clin Infect Dis 2000;31:869-874.

17. van der Eerden MM, Vlaspolder F, de Graaff CS, Groot T, Jansen HM, Boersma WG. Value of intensive diagnostic microbiological investigation in low- and high-risk patients with community-acquired pneumonia. Eur J Clin Microbiol Infect Dis 2005;24:241-249.

18. Musher DM, Montoya R, Wanahita A. Diagnostic value of microscopic examination of Gram-stained sputum and sputum cultures in patients with bacteremic pneumococcal pneumonia. Clin Infect Dis 2004;39:165-169.

19. McCauley LM, Webb BJ, Sorensen J, Dean NC. Use of tracheal aspirate culture in newly intubated patients with community-onset pneumonia. Ann Am Thorac Soc 2016;13:376-381.

20. Meehan TP, Fine MJ, Krumholz HM, Scinto JD, Galusha DH, Mockalis JT, et al. Quality of care, process, and outcomes in elderly patients with pneumonia. JAMA 1997;278:2080-2084.

21. Benenson RS, Kepner AM, Pyle DN II, Cavanaugh S. Selective use of blood cultures in emergency department pneumonia patients. $J$ Emerg Med 2007;33:1-8. 
22. Dedier J, Singer DE, Chang Y, Moore M, Atlas SJ. Processes of care, illness severity, and outcomes in the management of communityacquired pneumonia at academic hospitals. Arch Intern Med 2001; 161:2099-2104.

23. Campbell SG, Marrie TJ, Anstey R, Dickinson G, Ackroyd-Stolarz S. The contribution of blood cultures to the clinical management of adult patients admitted to the hospital with community-acquired pneumonia: a prospective observational study. Chest 2003;123:1142-1150.

24. Waterer GW, Wunderink RG. The influence of the severity of community-acquired pneumonia on the usefulness of blood cultures. Respir Med 2001;95:78-82.

25. Waterer GW, Jennings SG, Wunderink RG. The impact of blood cultures on antibiotic therapy in pneumococcal pneumonia. Chest 1999;116:1278-1281.

26. Metersky ML, Ma A, Bratzler DW, Houck PM. Predicting bacteremia in patients with community-acquired pneumonia. Am J Respir Crit Care Med 2004;169:342-347.

27. Costantini E, Allara E, Patrucco F, Faggiano F, Hamid F, Balbo PE. Adherence to guidelines for hospitalized community-acquired pneumonia over time and its impact on health outcomes and mortality. Intern Emerg Med 2016;11:929-940.

28. Falguera M, Ruiz-González A, Schoenenberger JA, Touzón C, Gázquez I, Galindo C, et al. Prospective, randomised study to compare empirical treatment versus targeted treatment on the basis of the urine antigen results in hospitalised patients with communityacquired pneumonia. Thorax 2010;65:101-106.

29. Piso RJ, Iven-Koller D, Koller MT, Bassetti S. The routine use of urinary pneumococcal antigen test in hospitalised patients with community acquired pneumonia has limited impact for adjustment of antibiotic treatment. Swiss Med Wkly 2012;142:w13679.

30. Garrison LE, Kunz JM, Cooley LA, Moore MR, Lucas C, Schrag S, et al. Vital signs: deficiencies in environmental control identified in outbreaks of legionnaires' disease. North America, 2000-2014. MMWR Morb Mortal Wkly Rep 2016;65:576-584.

31. Dooling KL, Toews KA, Hicks LA, Garrison LE, Bachaus B, Zansky S, et al. Active bacterial core surveillance for legionellosis: United States, 2011-2013. MMWR Morb Mortal Wkly Rep 2015;64:1190-1193.

32. Uyeki TM. Preventing and controlling influenza with available interventions. N Engl J Med 2014;370:789-791.

33. Uyeki TM, Bernstein HH, Bradley JS, Englund JA, File TM Jr, Fry AM, et al. Clinical practice guidelines by the Infectious Diseases Society of America: 2018 update on diagnosis, treatment, chemoprophylaxis, and institutional outbreak management of seasonal influenzaa. Clin Infect Dis 2018;68:e1-e47.

34. Musher DM, Thorner AR. Community-acquired pneumonia. N Engl J Med 2014;371:1619-1628.

35. Christ-Crain M, Stolz D, Bingisser R, Müller C, Miedinger D, Huber PR, et al. Procalcitonin guidance of antibiotic therapy in communityacquired pneumonia: a randomized trial. Am J Respir Crit Care Med 2006;174:84-93.

36. Schuetz P, Müller B, Christ-Crain M, Stolz D, Tamm M, Bouadma L, et al. Procalcitonin to initiate or discontinue antibiotics in acute respiratory tract infections. Cochrane Database Syst Rev 2012;(9): CD007498.

37. Self WH, Balk RA, Grijalva CG, Williams DJ, Zhu Y, Anderson EJ, et al. Procalcitonin as a marker of etiology in adults hospitalized with community-acquired pneumonia. Clin Infect Dis 2017;65:183-190.

38. Kamat IS, Ramachandran V, Eswaran H, Abers MS, Musher DM. Low procalcitonin, community acquired pneumonia, and antibiotic therapy. Lancet Infect Dis 2018;18:496-497.

39. Fine MJ, Auble TE, Yealy DM, Hanusa BH, Weissfeld LA, Singer DE, et al. A prediction rule to identify low-risk patients with communityacquired pneumonia. N Engl J Med 1997;336:243-250.

40. Lim WS, van der Eerden MM, Laing R, Boersma WG, Karalus N, Town $\mathrm{Gl}$, et al. Defining community acquired pneumonia severity on presentation to hospital: an international derivation and validation study. Thorax 2003;58:377-382.

41. Aujesky D, Auble TE, Yealy DM, Stone RA, Obrosky DS, Meehan TP, et al. Prospective comparison of three validated prediction rules for prognosis in community-acquired pneumonia. Am J Med 2005;118: 384-392.
42. Marrie TJ, Lau CY, Wheeler SL, Wong CJ, Vandervoort MK, Feagan BG; CAPITAL Study Investigators. A controlled trial of a critical pathway for treatment of community-acquired pneumonia. JAMA 2000;283:749-755.

43. Yealy DM, Auble TE, Stone RA, Lave JR, Meehan TP, Graff LG, et al. Effect of increasing the intensity of implementing pneumonia guidelines: a randomized, controlled trial. Ann Intern Med 2005;143:881-894.

44. Carratalà J, Fernández-Sabé N, Ortega L, Castellsagué X, Rosón B, Dorca J, et al. Outpatient care compared with hospitalization for community-acquired pneumonia: a randomized trial in low-risk patients. Ann Intern Med 2005;142:165-172.

45. Atlas SJ, Benzer TI, Borowsky LH, Chang Y, Burnham DC, Metlay JP, et al. Safely increasing the proportion of patients with communityacquired pneumonia treated as outpatients: an interventional trial. Arch Intern Med 1998;158:1350-1356.

46. Jo S, Kim K, Jung K, Rhee JE, Cho IS, Lee CC, et al. The effects of incorporating a pneumonia severity index into the admission protocol for community-acquired pneumonia. J Emerg Med 2012;42:133-138.

47. Julián-Jiménez A, Palomo de los Reyes MJ, Parejo Miguez R, LaínTerés N, Cuena-Boy R, Lozano-Ancín A. Improved management of community-acquired pneumonia in the emergency department. Arch Bronconeumol 2013;49:230-240.

48. Renaud B, Coma E, Labarere J, Hayon J, Roy PM, Boureaux H, et al.; Pneumocom Study Investigators. Routine use of the Pneumonia Severity Index for guiding the site-of-treatment decision of patients with pneumonia in the emergency department: a multicenter, prospective, observational, controlled cohort study. Clin Infect Dis 2007;44:41-49.

49. Labarere J, Stone RA, Scott Obrosky D, Yealy DM, Meehan TP, Auble $\mathrm{TE}$, et al. Factors associated with the hospitalization of low-risk patients with community-acquired pneumonia in a clusterrandomized trial. J Gen Intern Med 2006;21:745-752.

50. Marrie TJ, Huang JQ. Low-risk patients admitted with communityacquired pneumonia. Am J Med 2005;118:1357-1363.

51. Dean NC, Jones BE, Jones JP, Ferraro JP, Post HB, Aronsky D, et al Impact of an electronic clinical decision support tool for emergency department patients with pneumonia. Ann Emerg Med 2015;66: 511-520.

52. Richards DA, Toop LJ, Epton MJ, McGeoch GR, Town GI, Wynn-Thomas $\mathrm{SM}$, et al. Home management of mild to moderately severe community-acquired pneumonia: a randomised controlled trial. Med J Aust 2005;183:235-238.

53. Colice GL, Morley MA, Asche C, Birnbaum HG. Treatment costs of community-acquired pneumonia in an employed population. Chest 2004:125:2140-2145.

54. Yu H, Rubin J, Dunning S, Li S, Sato R. Clinical and economic burden of community-acquired pneumonia in the Medicare fee-for-service population. J Am Geriatr Soc 2012;60:2137-2143.

55. MDCalc. PSI/PORT score: pneumonia severity index for CAP [accessed 2019 Sept 8]. Available from: https://www.mdcalc.com/ psi-port-score-pneumonia-severity-index-cap.

56. Jones BE, Jones J, Bewick T, Lim WS, Aronsky D, Brown SM, et al. CURB-65 pneumonia severity assessment adapted for electronic decision support. Chest 2011;140:156-163.

57. Liapikou A, Ferrer M, Polverino E, Balasso V, Esperatti M, Piñer R, et al. Severe community-acquired pneumonia: validation of the Infectious Diseases Society of America/American Thoracic Society guidelines to predict an intensive care unit admission. Clin Infect Dis 2009;48: 377-385

58. Phua J, See KC, Chan YH, Widjaja LS, Aung NW, Ngerng WJ, et al. Validation and clinical implications of the IDSA/ATS minor criteria for severe community-acquired pneumonia. Thorax 2009;64:598-603.

59. Chalmers JD, Taylor JK, Mandal P, Choudhury G, Singanayagam A, Akram AR, et al. Validation of the Infectious Diseases Society of America/American Thoracic Society minor criteria for intensive care unit admission in community-acquired pneumonia patients without major criteria or contraindications to intensive care unit care. Clin Infect Dis 2011;53:503-511.

60. Charles PG, Wolfe R, Whitby M, Fine MJ, Fuller AJ, Stirling R, et al.; Australian Community-Acquired Pneumonia Study Collaboration. SMART-COP: a tool for predicting the need for intensive respiratory 
or vasopressor support in community-acquired pneumonia. Clin Infect Dis 2008;47:375-384.

61. Brown SM, Jones BE, Jephson AR, Dean NC; Infectious Disease Society of America/American Thoracic Society 2007. Validation of the Infectious Disease Society of America/American Thoracic Society 2007 guidelines for severe community-acquired pneumonia. Crit Care Med 2009;37:3010-3016.

62. Marti C, Garin N, Grosgurin O, Poncet A, Combescure C, Carballo S, et al. Prediction of severe community-acquired pneumonia: a systematic review and meta-analysis. Crit Care 2012;16:R141.

63. Chalmers JD, Mandal P, Singanayagam A, Akram AR, Choudhury G, Short PM, et al. Severity assessment tools to guide ICU admission in community-acquired pneumonia: systematic review and meta-analysis. Intensive Care Med 2011;37:1409-1420.

64. Brown SM, Jones JP, Aronsky D, Jones BE, Lanspa MJ, Dean NC. Relationships among initial hospital triage, disease progression and mortality in community-acquired pneumonia. Respirology 2012;17:1207-1213.

65. Phua J, Ngerng WJ, Lim TK. The impact of a delay in intensive care unit admission for community-acquired pneumonia. Eur Respir J 2010; 36:826-833.

66. Renaud B, Brun-Buisson C, Santin A, Coma E, Noyez C, Fine MJ, et al. Outcomes of early, late, and no admission to the intensive care unit for patients hospitalized with community-acquired pneumonia. Acad Emerg Med 2012;19:294-303.

67. Restrepo MI, Mortensen EM, Rello J, Brody J, Anzueto A. Late admission to the ICU in patients with community-acquired pneumonia is associated with higher mortality. Chest 2010;137:552-557.

68. Pakhale S, Mulpuru S, Verheij T, Kochen M, Rohde G, Bjerre L. Antibiotics for community-acquired pneumonia in adolescent and adult outpatients. 2014 [accessed 2017 Nov 19]. Available from: http://www.cochrane.org/CD002109/ARI_antibiotics-forcommunity-acquired-pneumonia-in-adolescent-and-adultoutpatients.

69. English ML, Fredericks CE, Milanesio NA, Rohowsky N, Xu ZQ, Jenta $\mathrm{TR}$, et al. Cethromycin versus clarithromycin for community-acquired pneumonia: comparative efficacy and safety outcomes from two double-blinded, randomized, parallel-group, multicenter, multinational noninferiority studies. Antimicrob Agents Chemother 2012;56:2037-2047.

70. Fogarty C, Grossman C, Williams J, Haverstock M, Church D. Efficacy and safety of moxifloxacin vs clarithromycin for community-acquired pneumonia. Infect Med 1999;16:748-763.

71. Fogarty CM, Cyganowski M, Palo WA, Hom RC, Craig WA. A comparison of cefditoren pivoxil and amoxicillin/clavulanate in the treatment of community-acquired pneumonia: a multicenter, prospective, randomized, investigator-blinded, parallel-group study. Clin Ther 2002;24:1854-1870.

72. Gotfried MH, Dattani D, Riffer E, Devcich KJ, Busman TA, Notario GF, et al. A controlled, double-blind, multicenter study comparing clarithromycin extended-release tablets and levofloxacin tablets in the treatment of community-acquired pneumonia. Clin Ther 2002;24:736-751.

73. Higuera F, Hidalgo H, Feris J, Giguere G, Collins JJ. Comparison of oral cefuroxime axetil and oral amoxycillin/clavulanate in the treatment of community-acquired pneumonia. J Antimicrob Chemother 1996;37: 555-564.

74. Kohno S, Watanabe A, Aoki N, Niki Y. Clinical evaluation of telithromycin for community-acquired pneumonia phase III doubleblind comparative study of telithromycin versus levofloxacin. Japanese Journal of Chemotherapy 2003;51:255-278.

75. Liu Y, Zhang Y, Wu J, Zhu D, Sun S, Zhao L, et al. A randomized, double-blind, multicenter phase II study comparing the efficacy and safety of oral nemonoxacin with oral levofloxacin in the treatment of communityacquired pneumonia. J Microbiol Immunol Infect 2017;50:811-820.

76. Bonvehi P, Weber K, Busman T, Shortridge D, Notario G. Comparison of clarithromycin and amoxicillin/clavulanic acid for communityacquired pneumonia in an era of drug-resistant Streptococcus pneumoniae. Clin Drug Investig 2003;23:491-501.

77. D'Ignazio J, Camere MA, Lewis DE, Jorgensen D, Breen JD. Novel, single-dose microsphere formulation of azithromycin versus 7-day levofloxacin therapy for treatment of mild to moderate communityacquired pneumonia in adults. Antimicrob Agents Chemother 2005; 49:4035-4041.
78. Salvarezza CR, Mingrone H, Fachinelli H, Kijanczuk S. Comparison of roxithromycin with cefixime in the treatment of adults with community-acquired pneumonia. J Antimicrob Chemother 1998;41: 75-80.

79. Tellier G, Niederman MS, Nusrat R, Patel M, Lavin B. Clinical and bacteriological efficacy and safety of 5 and 7 day regimens of telithromycin once daily compared with a 10 day regimen of clarithromycin twice daily in patients with mild to moderate community-acquired pneumonia. J Antimicrob Chemother 2004;54: 515-523.

80. van Rensburg DJ, Perng RP, Mitha IH, Bester AJ, Kasumba J, Wu RG, et al. Efficacy and safety of nemonoxacin versus levofloxacin for community-acquired pneumonia. Antimicrob Agents Chemother 2010;54:4098-4106.

81. Wiesner B, Wilen-Rosenqvist $G$, Lehtonen $L$. Twice daily dosing of erythromycin acistrate in the treatment of acute bronchitis and pneumonia. Arzneimittelforschung 1993;43:1014-1017.

82. Mathers Dunbar L, Hassman J, Tellier G. Efficacy and tolerability of once-daily oral telithromycin compared with clarithromycin for the treatment of community-acquired pneumonia in adults. Clin Ther 2004;26:48-62.

83. Oldach D, Clark K, Schranz J, Das A, Craft JC, Scott D, et al. Randomized, double-blind, multicenter phase 2 study comparing the efficacy and safety of oral solithromycin (CEM-101) to those of oral levofloxacin in the treatment of patients with community-acquired bacterial pneumonia. Antimicrob Agents Chemother 2013;57:2526-2534.

84. Rovira E, Martinez-Moragon E, Belda A, Gonzalvo F, Ripolles F, Pascual JM. Treatment of community-acquired pneumonia in outpatients: randomized study of clarithromycin alone versus clarithromycin and cefuroxime. Respiration 1999;66: 413-418.

85. Maimon N, Nopmaneejumruslers C, Marras TK. Antibacterial class is not obviously important in outpatient pneumonia: a meta-analysis. Eur Respir J 2008;31:1068-1076.

86. Petitpretz P, Arvis P, Marel M, Moita J, Urueta J; CAP5 Moxifloxacin Study Group. Oral moxifloxacin vs high-dosage amoxicillin in the treatment of mild-to-moderate, community-acquired, suspected pneumococcal pneumonia in adults. Chest 2001;119:185-195.

87. Aubier M, Verster R, Regamey C, Geslin P, Vercken JB; Sparfloxacin European Study Group. Once-daily sparfloxacin versus high-dosage amoxicillin in the treatment of community-acquired, suspected pneumococcal pneumonia in adults. Clin Infect Dis 1998;26: 1312-1320.

88. Hagberg L, Torres A, van Rensburg D, Leroy B, Rangaraju M, Ruuth E. Efficacy and tolerability of once-daily telithromycin compared with high-dose amoxicillin for treatment of community-acquired pneumonia. Infection 2002;30:378-386.

89. Siquier B, Sánchez-Alvarez J, García-Mendez E, Sabriá M, Santos J, Pallarés R, et al.; 620 Clinical Study Group. Efficacy and safety of twicedaily pharmacokinetically enhanced amoxicillin/clavulanate (2000/125 $\mathrm{mg}$ ) in the treatment of adults with community-acquired pneumonia in a country with a high prevalence of penicillin-resistant Streptococcus pneumoniae. J Antimicrob Chemother 2006;57:536-545.

90. Paris R, Confalonieri M, Dal Negro R, Ligia GP, Mos L, Todisco T, et al. Efficacy and safety of azithromycin $1 \mathrm{~g}$ once daily for 3 days in the treatment of community-acquired pneumonia: an open-label randomised comparison with amoxicillin-clavulanate $875 / 125 \mathrm{mg}$ twice daily for 7 days. $J$ Chemother 2008;20:77-86.

91. Mokabberi R, Haftbaradaran A, Ravakhah K. Doxycycline vs. levofloxacin in the treatment of community-acquired pneumonia. $J$ Clin Pharm Ther 2010;35:195-200.

92. Ailani RK, Agastya G, Ailani RK, Mukunda BN, Shekar R. Doxycycline is a cost-effective therapy for hospitalized patients with communityacquired pneumonia. Arch Intern Med 1999;159:266-270.

93. Lonks JR, Garau J, Gomez L, Xercavins M, Ochoa de Echagüen A, Gareen IF, et al. Failure of macrolide antibiotic treatment in patients with bacteremia due to erythromycin-resistant Streptococcus pneumoniae. Clin Infect Dis 2002;35:556-564.

94. Daneman N, McGeer A, Green K, Low DE; Toronto Invasive Bacterial Diseases Network. Macrolide resistance in bacteremic pneumococcal disease: implications for patient management. Clin Infect Dis 2006;43:432-438. 
95. Centers for Disease Control and Prevention. Active Bacterial Core surveillance (ABCs) report, Emerging Infections Program Network, Streptococcus pneumoniae, 2016 [accessed 2019 Sept 8]. Available from: https://www.cdc.gov/abcs/reports-findings/survreports/spneu16.pdf.

96. U.S. Food and Drug Administration. Fluoroquinolone antimicrobial drugs information. 2019 [accessed 2019 Mar 8]. Available from: https://www.fda.gov/Drugs/DrugSafety/InformationbyDrugClass/ ucm346750.htm.

97. Fogarty C, Siami G, Kohler R, File TM, Tennenberg AM, Olson WH, et al. Multicenter, open-label, randomized study to compare the safety and efficacy of levofloxacin versus ceftriaxone sodium and erythromycin followed by clarithromycin and amoxicillin-clavulanate in the treatment of serious community-acquired pneumonia in adults. Clin Infect Dis 2004;38:S16-S23.

98. Frank E, Liu J, Kinasewitz G, Moran GJ, Oross MP, Olson WH, et al. A multicenter, open-label, randomized comparison of levofloxacin and azithromycin plus ceftriaxone in hospitalized adults with moderate to severe community-acquired pneumonia. Clin Ther 2002; 24:1292-1308.

99. Lee JH, Kim SW, Kim JH, Ryu YJ, Chang JH. High-dose levofloxacin in community-acquired pneumonia: a randomized, open-label study. Clin Drug Investig 2012;32:569-576.

100. Lin TY, Lin SM, Chen HC, Wang CJ, Wang YM, Chang ML, et al. An open-label, randomized comparison of levofloxacin and amoxicillin/clavulanate plus clarithromycin for the treatment of hospitalized patients with community-acquired pneumonia. Chang Gung Med J 2007;30:321-332.

101. Portier H, Brambilla C, Garre M, Paganin F, Poubeau P, Zuck P. Moxifloxacin monotherapy compared to amoxicillin-clavulanate plus roxithromycin for nonsevere community-acquired pneumonia in adults with risk factors. Eur J Clin Microbiol Infect Dis 2005;24: 367-376.

102. Postma DF, van Werkhoven $\mathrm{CH}$, van Elden LJ, Thijsen SF, Hoepelman Al, Kluytmans JA, et al.; CAP-START Study Group. Antibiotic treatment strategies for community-acquired pneumonia in adults. N Engl J Med 2015;372:1312-1323.

103. Xu S, Xiong S, Xu Y, Liu J, Liu H, Zhao J, et al. Efficacy and safety of intravenous moxifloxacin versus cefoperazone with azithromycin in the treatment of community acquired pneumonia. J Huazhong Univ Sci Technolog Med Sci 2006;26:421-424.

104. Raz-Pasteur A, Shasha D, Paul M. Fluoroquinolones or macrolides alone versus combined with $\beta$-lactams for adults with communityacquired pneumonia: systematic review and meta-analysis. Int $J$ Antimicrob Agents 2015;46:242-248.

105. Lee JS, Giesler DL, Gellad WF, Fine MJ. Antibiotic therapy for adults hospitalized with community-acquired pneumonia: a systematic review. JAMA 2016;315:593-602.

106. Stets R, Popescu M, Gonong JR, Mitha I, Nseir W, Madej A, et al. Omadacycline for community-acquired bacterial pneumonia. $N$ Engl J Med 2019;380:517-527.

107. Garin N, Genné D, Carballo S, Chuard C, Eich G, Hugli O, et al. $\beta$-Lactam monotherapy vs $\beta$-lactam-macrolide combination treatment in moderately severe community-acquired pneumonia: a randomized noninferiority trial. JAMA Intern Med 2014;174:1894-1901.

108. Nie W, Li B, Xiu Q. $\beta$-Lactam/macrolide dual therapy versus $\beta$-lactam monotherapy for the treatment of community-acquired pneumonia in adults: a systematic review and meta-analysis. $J$ Antimicrob Chemother 2014;69:1441-1446.

109. Horita N, Otsuka T, Haranaga S, Namkoong H, Miki M, Miyashita N, et al. Beta-lactam plus macrolides or beta-lactam alone for community-acquired pneumonia: a systematic review and metaanalysis. Respirology 2016;21:1193-1200.

110. File TM Jr, Goldberg L, Das A, Sweeney C, Saviski J, Gelone SP, et al. Efficacy and safety of iv-to-oral lefamulin, a pleuromutilin antibiotic, for treatment of community-acquired bacterial pneumonia: the phase 3 LEAP 1 trial. Clin Infect Dis [online ahead of print] 4 Feb 2019; DOI: 10.1093/cid/ciz090.

111. Sligl WI, Asadi L, Eurich DT, Tjosvold L, Marrie TJ, Majumdar SR. Macrolides and mortality in critically ill patients with communityacquired pneumonia: a systematic review and meta-analysis. Crit Care Med 2014;42:420-432.
112. Vardakas KZ, Trigkidis KK, Falagas ME. Fluoroquinolones or macrolides in combination with $\beta$-lactams in adult patients hospitalized with community acquired pneumonia: a systematic review and meta-analysis. Clin Microbiol Infect 2017;23:234-241.

113. Gleeson K, Eggli DF, Maxwell SL. Quantitative aspiration during sleep in normal subjects. Chest 1997;111:1266-1272.

114. Marik PE. Aspiration pneumonitis and aspiration pneumonia. N Engl J Med 2001;344:665-671.

115. Marrie TJ, Durant $\mathrm{H}$, Kwan $\mathrm{C}$. Nursing home-acquired pneumonia: a case-control study. J Am Geriatr Soc 1986;34:697-702.

116. Jaoude P, Badlam J, Anandam A, El-Solh AA. A comparison between time to clinical stability in community-acquired aspiration pneumonia and community-acquired pneumonia. Intern Emerg Med 2014:9:143-150.

117. Bartlett JG, Gorbach SL. Treatment of aspiration pneumonia and primary lung abscess: penicillin G vs clindamycin. JAMA 1975;234: 935-937.

118. Cesar L, Gonzalez C, Calia FM. Bacteriologic flora of aspirationinduced pulmonary infections. Arch Intern Med 1975;135: 711-714.

119. El-Solh AA, Pietrantoni C, Bhat A, Aquilina AT, Okada M, Grover V, et al. Microbiology of severe aspiration pneumonia in institutionalized elderly. Am J Respir Crit Care Med 2003;167:1650-1654.

120. Marik PE, Careau P. The role of anaerobes in patients with ventilatorassociated pneumonia and aspiration pneumonia: a prospective study. Chest 1999;115:178-183.

121. Mier L, Dreyfuss D, Darchy B, Lanore JJ, Djedaïni K, Weber P, et al. Is penicillin $\mathrm{G}$ an adequate initial treatment for aspiration pneumonia? A prospective evaluation using a protected specimen brush and quantitative cultures. Intensive Care Med 1993;19:279-284.

122. American Thoracic Society; Infectious Diseases Society of America. Guidelines for the management of adults with hospital-acquired, ventilator-associated, and healthcare-associated pneumonia. $A m \mathrm{~J}$ Respir Crit Care Med 2005;171:388-416.

123. Kollef MH, Shorr A, Tabak YP, Gupta V, Liu LZ, Johannes RS. Epidemiology and outcomes of health-care-associated pneumonia: results from a large US database of culture-positive pneumonia. Chest 2005;128:3854-3862.

124. Attridge RT, Frei CR, Pugh MJ, Lawson KA, Ryan L, Anzueto A, et al. Health care-associated pneumonia in the intensive care unit: guideline-concordant antibiotics and outcomes. J Crit Care 2016; 36:265-271.

125. Attridge RT, Frei CR, Restrepo MI, Lawson KA, Ryan L, Pugh MJ, et al. Guideline-concordant therapy and outcomes in healthcareassociated pneumonia. Eur Respir J 2011;38:878-887.

126. Chalmers JD, Rother C, Salih W, Ewig S. Healthcare-associated pneumonia does not accurately identify potentially resistant pathogens: a systematic review and meta-analysis. Clin Infect Dis 2014;58:330-339.

127. Chen JI, Slater LN, Kurdgelashvili G, Husain KO, Gentry CA. Outcomes of health care-associated pneumonia empirically treated with guideline-concordant regimens versus community-acquired pneumonia guideline-concordant regimens for patients admitted to acute care wards from home. Ann Pharmacother 2013;47:9-19.

128. Dobler CC, Waterer G. Healthcare-associated pneumonia: a US disease or relevant to the Asia Pacific, too? Respirology 2013;18: 923-932.

129. Ewig S, Welte T. Adding fuel to the flames? It is time to leave HCAP. Respir Med 2012;106:1309-1310.

130. Grenier C, Pépin J, Nault V, Howson J, Fournier X, Poirier MS, et al. Impact of guideline-consistent therapy on outcome of patients with healthcare-associated and community-acquired pneumonia. $J$ Antimicrob Chemother 2011;66:1617-1624.

131. Jones BE, Jones MM, Huttner B, Stoddard G, Brown KA, Stevens VW, et al. Trends in antibiotic use and nosocomial pathogens in hospitalized Veterans with pneumonia at 128 medical centers, 2006-2010. Clin Infect Dis 2015;61:1403-1410.

132. Kamata K, Suzuki H, Kanemoto K, Tokuda Y, Shiotani S, Hirose Y, et al. Clinical evaluation of the need for carbapenems to treat community-acquired and healthcare-associated pneumonia. $J$ Infect Chemother 2015;21:596-603. 
133. Rothberg MB, Zilberberg MD, Pekow PS, Priya A, Haessler S, Belforti $\mathrm{R}$, et al. Association of guideline-based antimicrobial therapy and outcomes in healthcare-associated pneumonia. $J$ Antimicrob Chemother 2015;70:1573-1579.

134. Webb BJ, Dascomb K, Stenehjem E, Dean N. Predicting risk of drugresistant organisms in pneumonia: moving beyond the HCAP model. Respir Med 2015;109:1-10.

135. Webb BJ, Dascomb K, Stenehjem E, Vikram HR, Agrwal N, Sakata K, et al. Derivation and multicenter validation of the drug resistance in pneumonia clinical prediction score. Antimicrob Agents Chemother 2016;60:2652-2663.

136. Arancibia F, Bauer TT, Ewig S, Mensa J, Gonzalez J, Niederman MS, et al. Community-acquired pneumonia due to gram-negative bacteria and pseudomonas aeruginosa: incidence, risk, and prognosis. Arch Intern Med 2002;162:1849-1858.

137. Cillóniz C, Gabarrús A, Ferrer M, Puig de la Bellacasa J, Rinaudo M, Mensa J, et al. Community-acquired pneumonia due to multidrugand non-multidrug-resistant Pseudomonas aeruginosa. Chest 2016;150:415-425.

138. Falcone M, Russo A, Giannella M, Cangemi R, Scarpellini MG, Bertazzoni G, et al. Individualizing risk of multidrug-resistant pathogens in community-onset pneumonia. PLoS One 2015;10: e0119528.

139. Gross AE, Van Schooneveld TC, Olsen KM, Rupp ME, Bui TH, Forsung $\mathrm{E}$, et al. Epidemiology and predictors of multidrug-resistant community-acquired and health care-associated pneumonia. Antimicrob Agents Chemother 2014;58:5262-5268.

140. Jung JY, Park MS, Kim YS, Park BH, Kim SK, Chang J, et al. Healthcare-associated pneumonia among hospitalized patients in a Korean tertiary hospital. BMC Infect Dis 2011;11:61.

141. Jung WJ, Kang YA, Park MS, Park SC, Leem AY, Kim EY, et al. Prediction of methicillin-resistant Staphylococcus aureus in patients with non-nosocomial pneumonia. BMC Infect Dis 2013;13:370.

142. Metersky ML, Frei CR, Mortensen EM. Predictors of Pseudomonas and methicillin-resistant Staphylococcus aureus in hospitalized patients with healthcare-associated pneumonia. Respirology 2016;21:157-163.

143. Minejima E, Lou M, Nieberg P, Wong-Beringer A. Patients presenting to the hospital with MRSA pneumonia: differentiating characteristics and outcomes with empiric treatment. BMC Infect Dis 2014;14:252.

144. Pifarre R, Falguera M, Vicente-de-Vera C, Nogues A. Characteristics of community-acquired pneumonia in patients with chronic obstructive pulmonary disease. Respir Med 2007;101:2139-2144.

145. Polverino E, Cilloniz C, Menendez R, Gabarrus A, Rosales-Mayor E, Alcaraz V, et al. Microbiology and outcomes of community acquired pneumonia in non cystic-fibrosis bronchiectasis patients. $J$ Infect 2015;71:28-36.

146. Prina E, Ranzani OT, Polverino E, Cillóniz C, Ferrer M, Fernandez L, et al. Risk factors associated with potentially antibiotic-resistant pathogens in community-acquired pneumonia. Ann Am Thorac Soc 2015;12:153-160.

147. Rodrigo-Troyano A, Sibila $\mathrm{O}$. The respiratory threat posed by multidrug resistant Gram-negative bacteria. Respirology 2017;22: 1288-1299.

148. Shindo $Y$, Ito R, Kobayashi D, Ando M, Ichikawa M, Shiraki A, et al. Risk factors for drug-resistant pathogens in community-acquired and healthcare-associated pneumonia. Am J Respir Crit Care Med 2013:188:985-995.

149. Shorr AF, Myers DE, Huang DB, Nathanson BH, Emons MF, Kollef $\mathrm{MH}$. A risk score for identifying methicillin-resistant Staphylococcus aureus in patients presenting to the hospital with pneumonia. BMC Infect Dis 2013;13:268

150. Torre-Cisneros J, Natera C, Mesa F, Trikic M, Rodriguez-Bano J. Clinical predictors of methicillin-resistant Staphylococcus aureus in nosocomial and healthcare-associated pneumonia: a multicenter, matched case-control study. Eur J Clin Microbiol Infect Dis 2018; 37:51-56.

151. von Baum H, Welte T, Marre R, Suttorp N, Ewig S; CAPNETZ study group. Community-acquired pneumonia through Enterobacteriaceae and Pseudomonas aeruginosa: diagnosis, incidence and predictors. Eur Respir J 2010;35:598-605.
152. Wang PH, Wang HC, Cheng SL, Chang HT, Laio $\mathrm{CH}$. Selection of empirical antibiotics for health care-associated pneumonia via integration of pneumonia severity index and risk factors of drugresistant pathogens. J Formos Med Assoc 2016;115:356-363.

153. Wooten DA, Winston LG. Risk factors for methicillin-resistant Staphylococcus aureus in patients with community-onset and hospital-onset pneumonia. Respir Med 2013;107:1266-1270.

154. Wu HP, Chu CM, Lin CY, Yu CC, Hua CC, Yu TJ, et al. Liver cirrhosis and diabetes mellitus are risk factors for Staphylococcus aureus infection in patients with healthcare-associated or hospitalacquired pneumonia. Pulm Med 2016;2016:4706150.

155. Aliberti S, Reyes LF, Faverio P, Sotgiu G, Dore S, Rodriguez AH, et al.; GLIMP Investigators. Global initiative for methicillin-resistant Staphylococcus aureus pneumonia (GLIMP): an international, observational cohort study. Lancet Infect Dis 2016;16:1364-1376.

156. Restrepo MI, Babu BL, Reyes LF, Chalmers JD, Soni NJ, Sibila O, et al.; GLIMP. Burden and risk factors for Pseudomonas aeruginosa community-acquired pneumonia: a multinational point prevalence study of hospitalised patients. Eur Respir J 2018;52:1701190.

157. Carugati M, Franzetti F, Wiemken T, Kelley RR, Peyrani P, Blasi F, et al. De-escalation therapy among bacteraemic patients with community-acquired pneumonia. Clin Microbiol Infect 2015;21:936, e11-8.

158. Viasus D, Simonetti AF, Garcia-Vidal C, Niubo J, Dorca J, Carratala J. Impact of antibiotic de-escalation on clinical outcomes in community-acquired pneumococcal pneumonia. J Antimicrob Chemother 2017;72:547-553.

159. Cremers AJ, Sprong T, Schouten JA, Walraven G, Hermans PW, Meis $\mathrm{JF}$, et al. Effect of antibiotic streamlining on patient outcome in pneumococcal bacteraemia. J Antimicrob Chemother 2014;69: 2258-2264.

160. Yamana H, Matsui $H$, Tagami T, Hirashima J, Fushimi K, Yasunaga $H$. De-escalation versus continuation of empirical antimicrobial therapy in community-acquired pneumonia. J Infect 2016;73:314-325.

161. Buckel WR, Stenehjem E, Sorensen J, Dean N, Webb B. Broadversus narrow-spectrum oral antibiotic transition and outcomes in health care-associated pneumonia. Ann Am Thorac Soc 2017;14: 200-205.

162. Morel J, Casoetto J, Jospé R, Aubert G, Terrana R, Dumont A, et al. De-escalation as part of a global strategy of empiric antibiotherapy management: a retrospective study in a medico-surgical intensive care unit. Crit Care 2010;14:R225.

163. Leone M, Bechis C, Baumstarck K, Lefrant JY, Albanèse J, Jaber S, et al.; AZUREA Network Investigators. De-escalation versus continuation of empirical antimicrobial treatment in severe sepsis: a multicenter non-blinded randomized noninferiority trial. Intensive Care Med 2014;40:1399-1408.

164. Gutiérrez-Pizarraya A, Leone M, Garnacho-Montero J, Martin C, Martin-Loeches I. Collaborative approach of individual participant data of prospective studies of de-escalation in non-immunosuppressed critically ill patients with sepsis. Expert Rev Clin Pharmacol 2017;10: 457-465.

165. Jones BE, Brown KA, Jones MM, Huttner BD, Greene T, Sauer BC, et al. Variation in empiric coverage versus detection of methicillinresistant Staphylococcus aureus and Pseudomonas aeruginosa in hospitalizations for community-onset pneumonia across 128 US Veterans Affairs Medical Centers. Infect Control Hosp Epidemiol 2017;38:937-944.

166. Kalil AC, Metersky ML, Klompas M, Muscedere J, Sweeney DA, Palmer LB, et al. Management of adults with hospital-acquired and ventilator-associated pneumonia: 2016 clinical practice guidelines by the Infectious Diseases Society of America and the American Thoracic Society. Clin Infect Dis 2016;63:e61-e111.

167. Dangerfield B, Chung A, Webb B, Seville MT. Predictive value of methicillin-resistant Staphylococcus aureus (MRSA) nasal swab PCR assay for MRSA pneumonia. Antimicrob Agents Chemother 2014;58:859-864.

168. Parente DM, Cunha CB, Mylonakis E, Timbrook TT. The clinical utility of methicillin-resistant Staphylococcus aureus (MRSA) nasal screening to rule out MRSA pneumonia: a diagnostic meta-analysis with antimicrobial stewardship implications. Clin Infect Dis 2018;67:1-7. 
169. Rhodes A, Evans LE, Alhazzani W, Levy MM, Antonelli M, Ferrer R, et al. Surviving sepsis Campaign: international guidelines for management of sepsis and septic shock: 2016. Intensive Care Med 2017;43:304-377.

170. Confalonieri M, Urbino R, Potena A, Piattella M, Parigi P, Puccio G, et al. Hydrocortisone infusion for severe community-acquired pneumonia: a preliminary randomized study. Am J Respir Crit Care Med 2005;171:242-248.

171. Nafae RM, Ragab MI, Amany FM, Rashed SB. Adjuvant role of corticosteroids in the treatment of community-acquired pneumonia. Egypt J Chest Dis Tuberc 2013;62:439-445.

172. Blum CA, Nigro N, Briel M, Schuetz P, Ullmer E, Suter-Widmer I, et al. Adjunct prednisone therapy for patients with community-acquired pneumonia: a multicentre, double-blind, randomised, placebocontrolled trial. Lancet 2015;385:1511-1518.

173. Torres A, Sibila O, Ferrer M, Polverino E, Menendez R, Mensa J, et al. Effect of corticosteroids on treatment failure among hospitalized patients with severe community-acquired pneumonia and high inflammatory response: a randomized clinical trial. JAMA 2015;313: 677-686.

174. Horita N, Otsuka T, Haranaga S, Namkoong H, Miki M, Miyashita N, et al. Adjunctive systemic corticosteroids for hospitalized community-acquired pneumonia: systematic review and metaanalysis 2015 update. Sci Rep 2015;5:14061.

175. Siemieniuk RA, Meade MO, Alonso-Coello P, Briel M, Evaniew N, Prasad $\mathrm{M}$, et al. Corticosteroid therapy for patients hospitalized with community-acquired pneumonia: a systematic review and meta-analysis. Ann Intern Med 2015;163:519-528.

176. Briel M, Spoorenberg SMC, Snijders D, Torres A, Fernandez-Serrano S, Meduri GU, et al.; Ovidius Study Group; Capisce Study Group; STEP Study Group. Corticosteroids in patients hospitalized with community-acquired pneumonia: systematic review and individual patient data metaanalysis. Clin Infect Dis 2018;66: 346-354.

177. Chen LP, Chen JH, Chen Y, Wu C, Yang XH. Efficacy and safety of glucocorticoids in the treatment of community-acquired pneumonia: a meta-analysis of randomized controlled trials. World J Emerg Med 2015;6:172-178.

178. Keh D, Trips E, Marx G, Wirtz SP, Abduljawwad E, Bercker S, et al.; SepNet-Critical Care Trials Group. Effect of hydrocortisone on development of shock among patients with severe sepsis: the HYPRESS randomized clinical trial. JAMA 2016;316:1775-1785.

179. Waljee AK, Rogers MA, Lin P, Singal AG, Stein JD, Marks RM, et al. Short term use of oral corticosteroids and related harms among adults in the United States: population based cohort study. BMJ 2017;357:j1415.

180. Rodrigo C, Leonardi-Bee J, Nguyen-Van-Tam J, Lim WS. Corticosteroids as adjunctive therapy in the treatment of influenza. Cochrane Database Syst Rev 2016;3:CD010406.

181. Lee N, Choi KW, Chan PK, Hui DS, Lui GC, Wong BC, et al. Outcomes of adults hospitalised with severe influenza. Thorax 2010;65:510-515.

182. McGeer A, Green KA, Plevneshi A, Shigayeva A, Siddiqi N, Raboud J, et al.; Toronto Invasive Bacterial Diseases Network. Antiviral therapy and outcomes of influenza requiring hospitalization in Ontario, Canada. Clin Infect Dis 2007;45:1568-1575.

183. Lee EH, Wu C, Lee EU, Stoute A, Hanson H, Cook HA, et al. Fatalities associated with the $2009 \mathrm{H} 1 \mathrm{~N} 1$ influenza A virus in New York city. Clin Infect Dis 2010;50:1498-1504.

184. Siston AM, Rasmussen SA, Honein MA, Fry AM, Seib K, Callaghan WM, et al.; Pandemic H1N1 Influenza in Pregnancy Working Group. Pandemic 2009 influenza $\mathrm{A}(\mathrm{H} 1 \mathrm{~N} 1)$ virus illness among pregnant women in the United States. JAMA 2010;303:1517-1525.

185. Louie JK, Yang S, Acosta M, Yen C, Samuel MC, Schechter R, et al. Treatment with neuraminidase inhibitors for critically ill patients with influenza A (H1N1)pdm09. Clin Infect Dis 2012;55:1198-1204.

186. Dobson J, Whitley RJ, Pocock S, Monto AS. Oseltamivir treatment for influenza in adults: a meta-analysis of randomised controlled trials. Lancet 2015;385:1729-1737.

187. Venkatesan S, Myles PR, Leonardi-Bee J, Muthuri SG, Al Masri M, Andrews $\mathrm{N}$, et al. Impact of outpatient neuraminidase inhibitor treatment in patients infected with influenza $\mathrm{A}(\mathrm{H} 1 \mathrm{N1})$ pdm09 at high risk of hospitalization: an individual participant data metaanalysis. Clin Infect Dis 2017;64:1328-1334.

188. Metersky ML, Masterton RG, Lode H, File TM, Jr., Babinchak T. Epidemiology, microbiology, and treatment considerations for bacterial pneumonia complicating influenza. Int J Infect Dis 2012; 16:e321-e331.

189. Shieh WJ, Blau DM, Denison AM, Deleon-Carnes M, Adem P, Bhatnagar J, et al. 2009 pandemic influenza A (H1N1): pathology and pathogenesis of 100 fatal cases in the United States. Am J Pathol 2010;177:166-175.

190. Hageman JC, Uyeki TM, Francis JS, Jernigan DB, Wheeler JG, Bridges $\mathrm{CB}$, et al. Severe community-acquired pneumonia due to Staphylococcus aureus, 2003-04 influenza season. Emerg Infect Dis 2006;12:894-899.

191. Jean C, Louie JK, Glaser CA, Harriman K, Hacker JK, Aranki F, et al. Invasive group A streptococcal infection concurrent with 2009 H1N1 influenza. Clin Infect Dis 2010;50:e59-e62.

192. Paddock CD, Liu L, Denison AM, Bartlett JH, Holman RC, DeleonCarnes M, et al. Myocardial injury and bacterial pneumonia contribute to the pathogenesis of fatal influenza B virus infection. $J$ Infect Dis 2012;205:895-905.

193. Rodríguez AH, Avilés-Jurado FX, Díaz E, Schuetz P, Trefler SI, SoléViolán J, et al.; SEMICYUC/GETGAG Working Group. Procalcitonin (PCT) levels for ruling-out bacterial coinfection in ICU patients with influenza: a CHAID decision-tree analysis. J Infect 2016;72:143-151.

194. el Moussaoui R, de Borgie CA, van den Broek P, Hustinx WN, Bresser $P$, van den Berk GE, et al. Effectiveness of discontinuing antibiotic treatment after three days versus eight days in mild to moderatesevere community acquired pneumonia: randomised, double blind study. BMJ 2006;332:1355.

195. Siegel RE, Alicea M, Lee A, Blaiklock R. Comparison of 7 versus 10 days of antibiotic therapy for hospitalized patients with uncomplicated community-acquired pneumonia: a prospective, randomized, double-blind study. Am J Ther 1999;6:217-222.

196. Dunbar LM, Wunderink RG, Habib MP, Smith LG, Tennenberg AM, Khashab MM, et al. High-dose, short-course levofloxacin for community-acquired pneumonia: a new treatment paradigm. Clin Infect Dis 2003;37:752-760.

197. Leophonte P, Choutet P, Gaillat J, Petitpretz P, Portier H, Montestruc $\mathrm{F}$, et al. Efficacité comparée de la ceftriaxone dans un traitement de dix jours versus un traitement raccourci de cinq jours des pneumonies aigues communautaires de l'adulte hospitalisé avec facteur de risque [in French]. Med Mal Infect 2992;32:360-381.

198. Dimopoulos G, Matthaiou DK, Karageorgopoulos DE, Grammatikos AP, Athanassa Z, Falagas ME. Short- versus long-course antibacterial therapy for community-acquired pneumonia : a meta-analysis. Drugs 2008;68:1841-1854.

199. Li JZ, Winston LG, Moore DH, Bent S. Efficacy of short-course antibiotic regimens for community-acquired pneumonia: a metaanalysis. Am J Med 2007;120:783-790.

200. Tansarli GS, Mylonakis E. Systematic review and meta-analysis of the efficacy of short-course antibiotic treatments for communityacquired pneumonia in adults. Antimicrob Agents Chemother 2018; 62:e00635-18.

201. Krüger S, Ewig S, Papassotiriou J, Kunde J, Marre R, von Baum H, et al.; CAPNETZ Study Group. Inflammatory parameters predict etiologic patterns but do not allow for individual prediction of etiology in patients with CAP: results from the German competence network CAPNETZ. Respir Res 2009;10:65.

202. Pfister R, Kochanek M, Leygeber T, Brun-Buisson C, Cuquemelle E, Machado MB, et al. Procalcitonin for diagnosis of bacterial pneumonia in critically ill patients during $2009 \mathrm{H} 1 \mathrm{~N} 1$ influenza pandemic: a prospective cohort study, systematic review and individual patient data meta-analysis. Crit Care 2014; 18:R44.

203. Musher DM, Bebko SP, Roig IL. Serum procalcitonin level, viral polymerase chain reaction analysis, and lower respiratory tract infection. J Infect Dis 2014;209:631-633.

204. Halm EA, Fine MJ, Marrie TJ, Coley CM, Kapoor WN, Obrosky DS, et al. Time to clinical stability in patients hospitalized with community-acquired pneumonia: implications for practice guidelines. JAMA 1998;279:1452-1457. 
205. Zasowski E, Butterfield JM, McNutt LA, Cohen J, Cosler L, Pai MP, et al. Relationship between time to clinical response and outcomes among Pneumonia Outcomes Research Team (PORT) risk class III and IV hospitalized patients with community-acquired pneumonia who received ceftriaxone and azithromycin. Antimicrob Agents Chemother 2014:58:3804-3813.

206. Garin N, Felix G, Chuard C, Genné D, Carballo S, Hugli O, et al. Predictors and implications of early clinical stability in patients hospitalized for moderately severe community-acquired pneumonia. PLoS One 2016;11:e0157350.

207. Menéndez R, Torres A, Zalacaín R, Aspa J, Martín Villasclaras JJ, Borderías L, et al.; Neumofail Group. Risk factors of treatment failure in community acquired pneumonia: implications for disease outcome. Thorax 2004;59:960-965.

208. Menéndez R, Torres A, Rodríguez de Castro F, Zalacaín R, Aspa J, Martín Villasclaras JJ, et al.; Neumofail Group. Reaching stability in community-acquired pneumonia: the effects of the severity of disease, treatment, and the characteristics of patients. Clin Infect Dis 2004;39:1783-1790.

209. Arancibia F, Ewig S, Martinez JA, Ruiz M, Bauer T, Marcos MA, et al. Antimicrobial treatment failures in patients with communityacquired pneumonia: causes and prognostic implications. Am J Respir Crit Care Med 2000;162:154-160.
210. Uranga A, España PP, Bilbao A, Quintana JM, Arriaga I, Intxausti M, et al. Duration of antibiotic treatment in community-acquired pneumonia: a multicenter randomized clinical trial. JAMA Intern Med 2016;176:1257-1265.

211. Macdonald C, Jayathissa S, Leadbetter M. Is post-pneumonia chest X-ray for lung malignancy useful? Results of an audit of current practice. Intern Med J 2015;45:329-334.

212. Holmberg $H$, Kragsbjerg P. Association of pneumonia and lung cancer: the value of convalescent chest radiography and follow-up. Scand J Infect Dis 1993;25:93-100.

213. Little BP, Gilman MD, Humphrey KL, Alkasab TK, Gibbons FK, Shepard JA, et al. Outcome of recommendations for radiographic follow-up of pneumonia on outpatient chest radiography. AJR Am J Roentgenol 2014;202:54-59.

214. Tang KL, Eurich DT, Minhas-Sandhu JK, Marrie TJ, Majumdar SR. Incidence, correlates, and chest radiographic yield of new lung cancer diagnosis in 3398 patients with pneumonia. Arch Intern Med 2011;171:1193-1198.

215. Mortensen EM, Copeland LA, Pugh MJ, Fine MJ, Nakashima B, Restrepo MI, et al. Diagnosis of pulmonary malignancy after hospitalization for pneumonia. Am J Med 2010;123:66-71.

216. Moyer VA; U.S. Preventive Services Task Force. Screening for lung cancer: U.S. Preventive Services Task Force recommendation statement. Ann Intern Med 2014;160:330-338. 